\title{
A review of the genus Zavrelia (Diptera: Chironomidae)
}

\author{
ToRbJøRn EKREM and ELISABETH STUR
}

Norwegian University of Science and Technology, Museum of Natural History and Archaeology, NO-7491 Trondheim, Norway; e-mails: Torbjorn.Ekrem@vm.ntnu.no; Elisabeth.Stur@vm.ntnu.no

Key words. Chironomidae, Zavrelia, generic diagnosis, keys, taxonomy, immature stages

\begin{abstract}
In this paper we review the taxonomy of the genus Zavrelia Kieffer, Thienemann \& Bause and present emended generic diagnoses of all major life stages. Illustrated keys to larvae, pupae, adult males and females are presented as well as descriptions of four species new to science. Zavrelia species are only recorded from the northern hemisphere and comprise in total ten small to minute species. The following life stages and species are described: Larva, pupa, adult male and adult female of Zavrelia aristata sp. n., Zavrelia hudsoni sp. n., Zavrelia pentatoma Kieffer \& Bause and Zavrelia sinica sp. n.; pupa and adult male of Zavrelia casasi sp. n.; and adult males of Zavrelia clinovolsella Guo \& Wang and Zavrelia tusimatijea (Sasa \& Suzuki). Zavrelia atrofasciata Kieffer and Stempellina paludosa Goetghebuer are proposed as new junior synonyms of Zavrelia pentatoma and lectotypes of Zavrelia nigritula, Zavrelia pentatoma and Stempellina paludosa are designated.
\end{abstract}

\section{INTRODUCTION}

Species of the genus Zavrelia Kieffer, Thienemann \& Bause in Bause (1913) are small to minute chironomids (non-biting midges), which are recorded from both continents of the northern hemisphere. Zavrelia species seem to be less common than species of their presumed sister genus Stempellinella, but when encountered, the larvae and pupae of Zavrelia are normally found in unpolluted streams and rivers. One exception is the western Palaearctic species Zavrelia pentatoma which is so far only recorded from standing waters rich in humic acids on or near moors. All known larvae of Zavrelia species construct small, straight transportable cases of sand, silt, detritus and sometimes diatoms that function as retreats until the mature pupa swims to the surface prior to adult emergence.

The argument for the erection of the genus Zavrelia was presented in part as personal communication from Kieffer (Bause, 1913, p. 100), but since the genus is defined by both larval and pupal characters in the identification key provided in the same work (op. cit. p. 42-45 \& p. 89-93), the authorship of the genus must also be credited to Bause. In addition, a footnote in the final chapter (p. 118) states that Thienemann must be regarded as author of the presented classification in which the diagnostic characters are commented on. Thus, we agree with Spies (2005) that Kieffer, Thienemann and Bause all must be credited with the authorship of Zavrelia.

Until recently, there were few Zavrelia species known to science. The Catalogue of Palaearctic Diptera (Ashe \& Cranston, 1990) and the later Manual of Palaearctic Diptera (Sæther et al., 2000) both list three valid species from the Palaearctic region. One of these, Zavrelia kibunensis Tokunaga, 1938, was transferred to the genus Neozavrelia (Ekrem, 2006), and Zavrelia atrofasciata is below regarded as a junior synonym of $Z$. pentatoma. In addition, Zavrelia inopinata Botnariuc \& Cindea-Cure,
1954, listed as doubtful species in the Palaearctic catalogue, is regarded as a junior synonym of Stempellinella ciliaris Goetghebuer, 1944 by Ekrem (2007). At least one Zavrelia species was recognised previously in the Nearctic, but none have been described formally and named from this region yet (Epler, 2001; Oliver et al., 1990). Regarding the Afrotropical region, Kieffer (1923) described Zavrelia kribiensis from southern Africa and Cameroon and the species was maintained by Freeman (1958). However, Z. kribiensis is morphologically quite different from other Zavrelia species in all life stages and was placed in a new genus Afrozavrelia by Harrison (2004). The Catalogue of the Diptera of the Oriental Region (Sublette \& Sublette, 1973) lists one unnamed species from Java reported by Zavřel (1934), but not described so it is not possible to say if it is a Zavrelia or a member of the more widely distributed genus Stempellinella.

More recently, Tanytarsus tusimatijeus Sasa \& Suzuki, 1999 was described from Tsushima Island (Sasa \& Suzuki, 1999) and transferred to Zavrelia by Ekrem (2006). In addition, two new species of Zavrelia were described from China (Guo \& Wang, 2004, 2007) and another two from Russia (Zorina, 2008). Including the four species new to science described below, the genus Zavrelia now contains a total of ten species.

Systematically, the genus Zavrelia is placed within the subtribe Zavreliina of the tribe Tanytarsini in the subfamily Chironominae (Ekrem \& Sæther, 2000; Sæther \& Roque, 2004). Morphologically, the genus is similar to its presumed sister genus Stempellinella, particularly in the immature stages. Some characters in particular seem to be useful for separating the two genera (see Ekrem, 2007, Table II, p. 1374), although examination of more associated Zavrelia pupae has revealed that not all species have shagreen on pleura II and that it is not necessarily arranged in distinct rows (this character was erroneously 
listed under Stempellinella by Ekrem, 2007). Preliminary phylogenetic analyses based on two nuclear and three mitochondrial markers indicate that the two genera are indeed separate monophyletic groups and thus should be maintained as entities at the same taxonomic level (Ekrem, in prep.).

The main aim of this study was to revise and describe known and previously unknown species in the genus Zavrelia and present identification keys to all major life stages as well as an emended diagnosis of the genus.

\section{MATERIAL AND METHODS}

We did some field work in Germany to supplement material on loan from collections and colleagues in Europe, North America and Asia.

The morphological terminology and abbreviations follow Sæther (1980). The term "taeniate" (Langton, 1994) is used for the flattened setae on the pupal exuviae, and the term "setiger", introduced by Spies (1998), is used for the setae-bearing part of the superior volsella of the male hypopygium. The following additional abbreviations are used: AAR - larval antennal pedestal/antennal segment 1 length ratio; AHR - larval antennal pedestal/head length ratio; L - larva; Lex - larval exuviae; LP associated larva and pupa; LP + - associated larva, pupa and adult female; LP $\widehat{0}$ - associated larva, pupa and adult male; LOR - lauterborn organ/antennal segments 3-5 length ratio; MVR - mentum/ventromental plate width ratio; $\mathrm{P}$ - pupa; Pex pupal exuviae; $\mathrm{P} \uparrow$ - associated pupa and adult female; $\mathrm{P} \hat{\sigma}-$ associated pupa and adult male.

Measurements are given as ranges, followed by the mean with the number of observed specimens in parenthesis if different from the number included in the description. Measurement methods follow Soponis (1977). The antennal ratio (AR) is measured on 10 flagellomeres. The lengths of the male genital volsellae were measured along their median margin, and of the anal point from the anterior ends of the anal crests to the anal point apex. In the larvae, the antennal pedestal length was measured along the median pedestal margin, excluding spur; antennal segments were measured from their base to the non-sclerotized apex, Lauterborn organs and pedicels were measured separately. All described larvae are fourth instar.

Collections (with abbreviations used in the text) in which material is deposited: $\mathrm{CNC}-$ Canadian National Collections, Ottawa, Ontario, Canada; NSMT - National Science Museum, Tokyo, Japan; NKUM - College of Life Science, Nankai University, Tianjin, China; PLH - Private collection of Pat L. Hudson, Ann Arbor, Michigan, USA; IRSNB - Royal Belgian Institute of Natural Sciences, Brussels, Belgium; UMSP - University of Minnesota, St. Paul, Minnesota, USA; USNM National Museum of Natural History (Smithsonian Institution), Washington, DC, USA; NTNU - Museum of Natural History and Archaeology, Norwegian University of Science and Technology, Trondheim, Norway; WG - Wojciech Giłka, University of Gdańsk, Poland; MZH - Zoological Museum, University of Helsinki, Finland; ZSM - Zoologische Staatssammlung München, Munich, Germany.

\section{RESULTS}

\section{Generic diagnosis}

Zavrelia Kieffer, Thienemann \& Bause in Bause, 1913

Type species. Zavrelia pentatoma Kieffer \& Bause in Bause, 1913, by monotypy (Bause, 1913: 73).

\section{Imago}

Small species, wing length about $0.8-1.5 \mathrm{~mm}$. Body with ground colour green or light brown or brown to black; vittae distinct if ground colour light.

Antenna. 10 easily discernible flagellomeres in male (distribution of antennal setae indicate 13 flagellomeres); 5 flagellomeres in female. Male antennal ratio 0.5-1.4.

Head. Eye hairy, without dorsomedian extension; frontal tubercles small to well developed; palp normally developed.

Thorax. Antepronotal lobes widely separated; scutum overreaching antepronotum; scutal tubercle absent; antepronotals absent; acrostichals present; up to 9 uniserial dorsocentrals; humerals absent or present; 1 prealar; supraalars absent; 2-7 scutellars.

Wing. Membrane with setae in all cells except anterior to vein $\mathrm{M}$; all veins with setae except $\mathrm{M}$ and $\mathrm{Sc}$. Costa not produced; $\mathrm{R}_{4+5}$ ending proximal to apex of $\mathrm{M}_{3+4}$; anal lobe not developed; squama bare. Female with slightly more setae on wing compared to male, but $\mathrm{M}$, Sc and cells anterior to $\mathrm{M}$ bare.

Legs. Apex of fore tibia with short, slender spur. Combs of mid and hind tibiae small, both bearing spurs, often one long and one short. Sensilla chaetica apparently absent from all tarsomeres. Pulvilli absent.

Male hypopygium. Anal tergite bands at least partially encircling several long median tergite setae placed at distance from anal point base, or median setae absent; laterosternite IX usually with seta. Anal point well developed, tapering distally, with long or short anal crests, extending onto anal tergite, with or without spinules and/or microtrichia in between. Setiger of superior volsella short, flattened, with digitiform or acute, medially directed tip; with 2 robust setae on distal inner margin; digitus absent. Median volsella very short, with distal clump of several long, slightly curved, setiform and lamelliform lamellae. Inferior volsella well developed, extending beyond base of gonostylus, sometimes nearly reaching apex of gonostylus, with few robust, curved setae distally, microtrichia absent at least dorsolaterally, basal wart absent. Gonostylus short, without apical tooth.

Female genitalia. Tergite IX semicircular. Sternite VIII with 20-35 setae. Gonocoxapodeme VIII strong, often with large anterior and posterior lobes. Sternite VIII sometimes forming narrow rim along lateral sides of vagina, floor absent. Gonapophysis VIII simple, with relatively long, posteromedially directed microtrichia. Apodeme lobe not apparent. Notum short or long, often as long as or slightly longer than width of seminal capsules; rami slightly diverging. Gonocoxite IX small, with few setae. Postgenital plate triangular, wide at base. Cercus can be as long as width of seminal capsules, but is usually shorter. Two seminal capsules present, almost circular, with small to large neck. Spermathecal ducts of variable length.

Pupa

Small, 2-3 mm long. Cephalothorax and lateral margins of segments VII-VIII of pupal exuviae light brown. 
Cephalothorax. Frontal apotome smooth or slightly rugose. Frontal setae long, taeniate; cephalic tubercles conical or absent. Frontal warts absent. Thoracic horn elongate, tapered, apical $1 / 4$ to whole horn with scattered short chaetae; base dome-like. Thorax usually finely granulose dorsally, occasionally strongly rugose. Three precorneals and two antepronotals taeniate, one antepronotal sensillum basiconicum. Two pairs of dorsocentrals present, all simple or $\mathrm{Dc}_{1}$ taeniate. Prealar tubercle inconspicuous to well developed; scutal tubercle absent. Wing sheath with prominent nose, pearl row absent.

Abdomen. Tergite I without microspinules or shagreen; TII-VI extensively covered with fine microspinules, which are partially or completely separated by bare median patch; microspinule patch on TII starting at or anterior to seta $\mathrm{D}_{1}$. TVII and VIII and anal lobe with lateral patches of fine spinules and shagreen. Conjunctives bare; pleura of segments IV-V always with shagreen, often also pleura of segments II, III and/or VI with shagreen. Hook row continuous, covering about $1 / 3$ of width of segment. Pedes spurii A present on segment IV; pedes spurii B on segment II well developed, rounded. Sternite I without anterolateral or anteromedian tubercles. Sternites without conspicuous armature. Segment VIII with single or sometimes bifurcate dark, posterolateral spur. Abdominal lateral setation variable: Segment II with 3 fine setae; III usually with 3 taeniate setae or 3 fine setae; IV with 3 taeniate setae or 2-3 fine setae and 0-1 taeniate seta; V with 3 or 4 taeniate setae; VI-VII each with 4 taeniate setae; VIII with 3 or 4 taeniate setae. Anal lobes moderately well developed, with complete fringe of 15-25 taeniate setae in single row and one dorsal seta on lobe.

Larva

Small, 2-2.5 mm long, case c. $2.5-3 \mathrm{~mm}$ long.

Head. Antenna 5-segmented, placed on tall pedestal with strong distal spur; basal segment about as long as flagellum or shorter, with ring organ and short seta basally. Antennal blade extending beyond antennal apex; segment 2 longer than more distal segments, bearing style and alternate Lauterborn organs. Lauterborn organs large, bulbous, one arising in proximal half or middle of segment 2, other apically, both placed on short pedicels, distal pedicel often slightly longer. Labral seta SI and chaetae pectinate, bases fused; SII pectinate or slightly plumose, placed on tall pedestal. Chaetulae and clypeal seta S3 simple or split in several branches; SIV present. Labral lamella well developed. Pecten epipharyngis consisting of 3 small chaetae and a broad anterior scale. Premandible with 4 teeth and well developed brush; teeth almost at right angles to main axis of premandible. Mandible with dorsal tooth, apical tooth and 3 inner teeth, all pale brown. Seta subdentalis long, slender, reaching well beyond tip of mandible. Seta interna consisting of 4 plumose branches. Pecten mandibularis with moderately long lamellae; mola with 1-2 spines. Mentum with pale brown teeth medially, slightly darker laterally, or uniformly pale brown. Median tooth rounded; with 6 pairs of lateral teeth, regularly slightly decreasing in size laterally.
Ventromental plates fan-shaped, separated medially by width of the median 5 mental teeth, not as wide as mentum. Postoccipital plate well developed, continuous.

Body. Anterior parapods with simple spines; posterior parapods with 16-18 simple claws. Two pairs of anal tubules. Supraanal seta well developed. Procercus with 2 small and 4 long anal setae, the short setae situated individually and not on the common base of the long setae.

\section{Diagnostic characters}

Zavrelia species can be separated from other genera in the tribe Tanytarsini by the following characters.

Male imago: Eye hairy, without dorsomedian elongation; antenna with 10 flagellomeres; wing hairy, with costa ending proximal to tip of vein $\mathrm{M}_{3+4}$; subcosta bare; combs of mid and hind tibia separate, both bearing spur; hypopygium with anal tergite setae placed at distance from anal point base, median volsella short and stout with rosette of subulate and simple lamellae.

Female imago: Eye hairy, without dorsomedian elongation; antenna with 5 flagellomeres; wing hairy, with costa ending proximal to tip of vein $\mathrm{M}_{3+4}$; subcosta bare; combs of mid and hind tibia separate, both bearing spur; genitalia without floor under vagina, gonapophyses VIII undivided.

Pupa: Frontal seta long, taeniate; thoracic horn elongate, tapered, with small chaetae; tergites II-VI with extensive fields of microspinules and shagreen, patches on tergite II starting anterior to seta $\mathrm{D}_{1}$; segments V-VIII and usually segment IV with taeniate lateral setae; pedes spurii A and B present; segment VIII with single or occasionally bifurcate posterolateral spur.

Larva: Antennal pedestal with single apical spur; antenna with alternate Lauterborn organs on antennal segment 2; premandible with 4 teeth; ventromental plates separated by at least the width of 3 median mental teeth; postoccipital plate well developed, continuous.

\section{Species descriptions \\ Zavrelia aristata sp. $\mathbf{n}$.}

Zavrelia sp.: Epler, 2001: chapter 8, p.170.

Zavrelia n. sp. 1: Bolton, 2007: 54.

\section{Diagnostic characters}

Zavrelia aristata can be separated from other Zavrelia species by the following combination of characters. Length of adult male c. $1.6 \mathrm{~mm}$; AR about 0.9 ; frontal tubercle small, conical; anal point without spinules but with numerous microtrichiae between long, high crests; 6-11 strong median tergite setae placed at some distance from anal point base; anal tergite with 22-32 apical setae; superior volsella digitiform, with small acute dorsomedially pointed apex; median volsella short, stout, with simple and subulate lamellae. Adult female with AR c. 0.25; vaginal floor absent, lateral margin of vagina without ventral extension; spermathecal duct longer than notum and rami combined, c. $220 \mu \mathrm{m}$ long; notum about the same length as rami; diameter of seminal capsule c. 50 $\mu \mathrm{m}$, slightly shorter than length of notum; cercus short, $\mathrm{c}$. $37 \mu \mathrm{m}$ long. Pupa with well developed, conical cephalic 

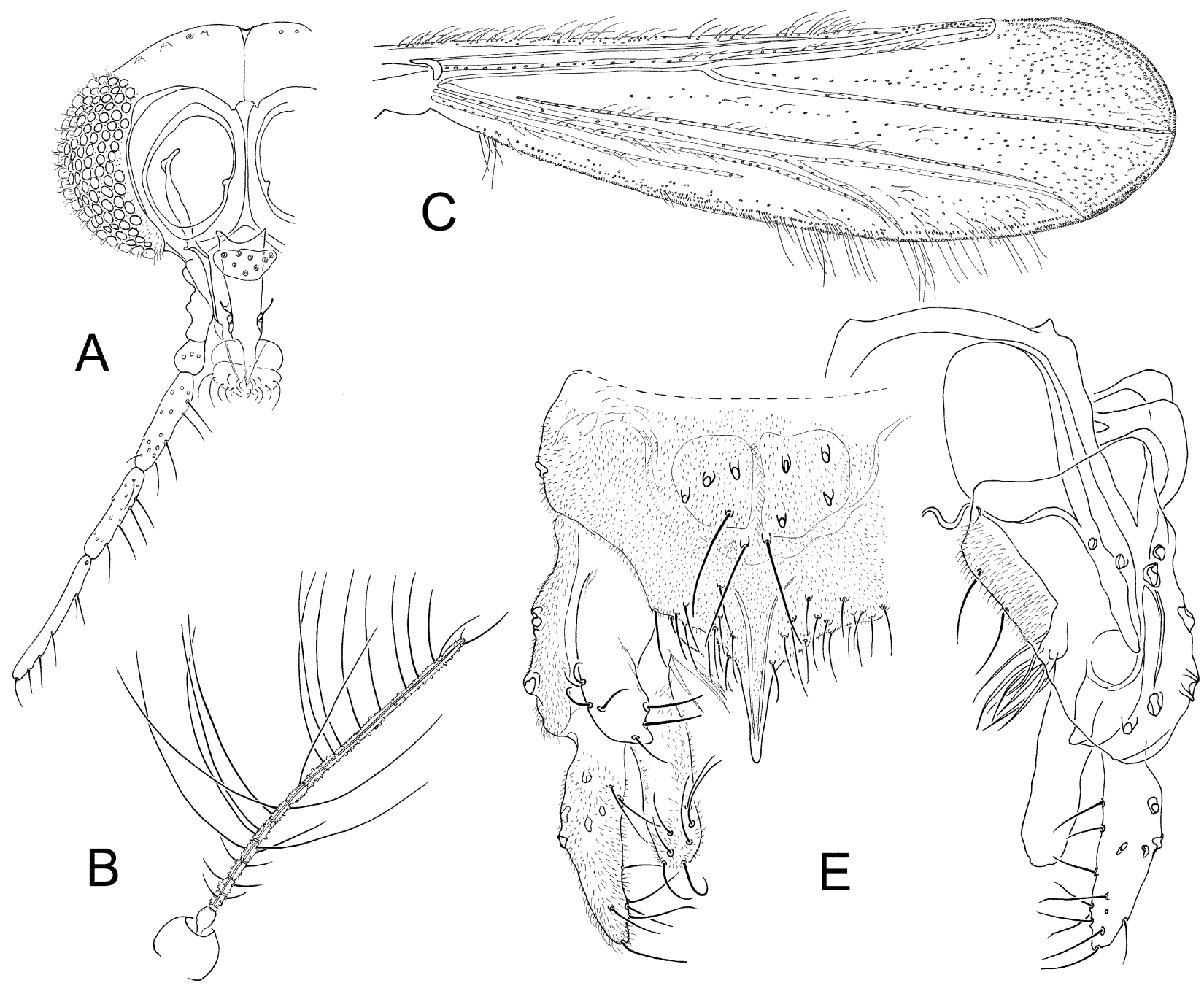

G
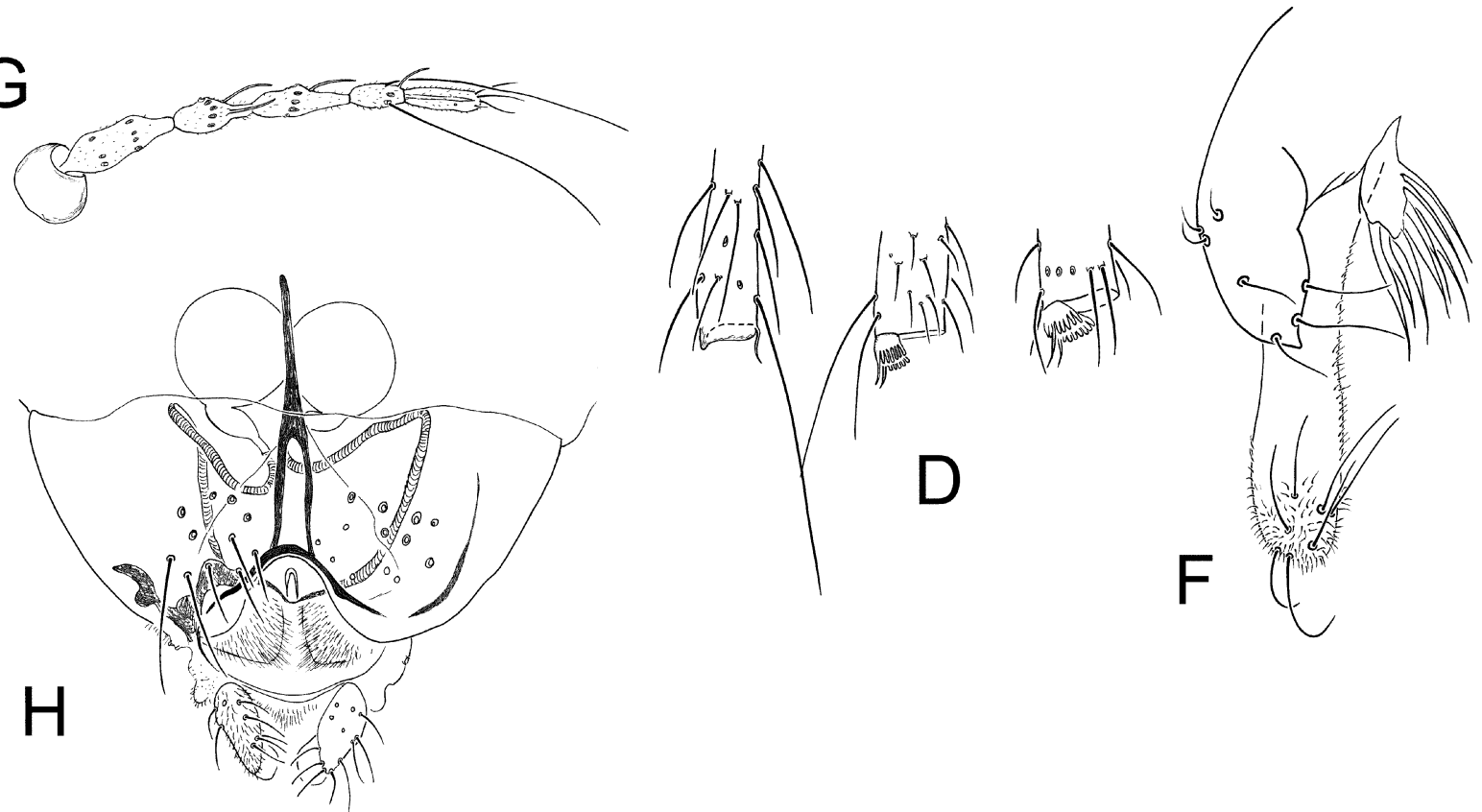

Fig. 1. Zavrelia aristata sp. n., imagines. (A-F) male: (A) head; (B) antenna; (C) wing; (D) apex of fore, mid and hind tibia; (E) hypopygium, dorsal and ventral view; $(\mathrm{F})$ superior, median and inferior volsella. $(\mathrm{G}-\mathrm{H})$ female: $(\mathrm{G})$ antenna; $(\mathrm{H})$ genitalia. 
TABLE 1. Leg segment lengths and ratios of adult Zavrelia. Data given as ranges, followed by the mean and number of specimens included in parentheses if different from total number measured for each species.

\begin{tabular}{|c|c|c|c|c|c|c|c|}
\hline Parameter & $\begin{array}{c}\text { aristata } \\
(\mathrm{n}=6)\end{array}$ & $\begin{array}{l}\text { casasi } \\
(\mathrm{n}=3)\end{array}$ & $\begin{array}{c}\text { clinovolsella } \\
(\mathrm{n}=1)\end{array}$ & $\begin{array}{c}\text { hudsoni } \\
(\mathrm{n}=1)\end{array}$ & $\begin{array}{l}\text { pentatoma } \\
(\mathrm{n}=5)\end{array}$ & $\begin{array}{l}\text { sinica } \\
(\mathrm{n}=3)\end{array}$ & $\begin{array}{l}\text { tusimatijea } \\
(\mathrm{n}=1)\end{array}$ \\
\hline Male fore femur & $375-480,428$ & $325-360,345$ & 400 & 550 & $480-586,524$ & $440-480,453$ & 530 \\
\hline Male fore tibia & 255-350, 299 & $240-250,245$ & 275 & 400 & $336-432,376$ & $310-360,330$ & 400 \\
\hline Male fore tarsus 1 & $420-530,465(5)$ & $285(1)$ & 460 & 540 & $480-576,520$ & $518(1)$ & 580 \\
\hline Male fore tarsus 2 & $215-285,249$ & $150(1)$ & 260 & 310 & $278-336,306$ & $298(1)$ & 340 \\
\hline Male fore tarsus 3 & $160-225,191$ & $130(1)$ & 200 & 250 & $216-264,231$ & $221(1)$ & 250 \\
\hline Male fore tarsus 4 & $110-150,132$ & $80(1)$ & 150 & 160 & $130-154,140$ & $163(1)$ & 170 \\
\hline Male fore tarsus 5 & $50-70,58$ & $50(1)$ & 70 & 75 & $58-72,67$ & $72(1)$ & 90 \\
\hline Male $\mathrm{LR}_{1}$ & $1.47-1.65,1.55$ & $1.16(1)$ & 1.67 & 1.35 & $1.30-1.50,1.40$ & $1.44(1)$ & 1.45 \\
\hline Male $\mathrm{BR}_{1}$ & $3.3-4.0,3.5$ & - & 3.0 & 4.0 & $3.0-3.7,3.4$ & $3.3(1)$ & 1.8 \\
\hline Male $\mathrm{BV}_{1}$ & $1.85-1.96,1.89$ & $2.15(1)$ & 1.67 & 1.87 & $1.87-1.93,1.90$ & $1.80(1)$ & 1.78 \\
\hline Male $\mathrm{SV}_{1}$ & $1.50-1.68,1.57$ & $2.08(1)$ & 1.47 & 1.76 & $1.62-1,79,1.72$ & $1.62(1)$ & 1.60 \\
\hline Male $\mathrm{LR}_{2}$ & $0.59-0.63,0.62$ & $0.62-0.65(2)$ & 0.64 & 0.59 & $0.53-0.59,0.56$ & $0.63-0.64$ & 0.54 \\
\hline Male $\mathrm{BR}_{2}$ & $4.0-6.5,5.7$ & - & 4.0 & 6.3 & $5.0-8.5,5.9$ & $4.0-5.0,4.6$ & 5.0 \\
\hline Male $\mathrm{LR}_{3}$ & $0.62-0.65,0.64$ & $0.63(3)$ & 0.67 & 0.52 & $0.55-0.59,0.58$ & 0.56 & 0.32 \\
\hline Male $\mathrm{BR}_{3}$ & $5.0-11.0,6.9$ & - & 4.7 & 6.0 & $5.5-7.4,6.1$ & $4.7-8.6,7.2$ & 7.2 \\
\hline Female $L_{1}$ & $1.41(1)$ & - & - & 1.5 & 1.33 & 1.47 & - \\
\hline
\end{tabular}

tubercle; thoracic horn c. $260 \mu \mathrm{m}$ long and thin with numerous small chaetae scattered over almost whole length of horn; thorax smooth except for small area of granulation along scutal suture and posterior to thoracic horn; anterior dorsocentrals as long as posterior dorsocentrals; microspinule patches on tergite II-IV large, starting at or anterior to seta $\mathrm{D}_{1}$; microspinule patches on tergites $\mathrm{V}$ and $\mathrm{VI}$ two broad longitudinal rows, which can be connected anteriorly; pleura III-V with shagreen; segment V with 4 lateral taeniate setae; anal lobe with fringe of 15-16 taeniate setae. Larva with well developed (c. 25-30 $\mu \mathrm{m}$ long) digitiform spur on antennal pedestal; antennal segment $165-70 \mu \mathrm{m}$ long; AR c. 0.9 ; antennal blade c. $130 \mu \mathrm{m}$ long; distal Lauterborn organ on $7 \mu \mathrm{m}$ long pedicel, basal Lauterborn organ on $5 \mu \mathrm{m}$ pedicel, placed at 1/3 length of antennal segment $2 ; \mathrm{S} 3$ simple.

\section{Description}

Adult male ( $\mathrm{n}=6$, unless otherwise stated). Length $1.3-1.8,1.6 \mathrm{~mm}$; wing length $0.88-1.26,1.06$.

Colour: Body and head ground colour light yellowishbrown, darker antennae, scutal stripes, median anepisternum, epimeron II, preepisternum and postnotum. Scutellum, haltere, legs and palpomeres pale yellow, eyes dark brown.

Head (Fig. 1A): Frontal tubercle comparatively small, 5-10, $8 \mu \mathrm{m}$ long; Antenna (Fig. 1B) with AR 0.87-0.97, 0.93 ; lengths of palpomeres (in $\mu \mathrm{m}$ ): $20-25,23 ; 25-30$, $27 ; 80-105,93 ; 75-100,88 ; 100-135,123$. Clypeus about $30 \mu \mathrm{m}$ long with $6-11,9$ setae; tentorium c. $95 \mu \mathrm{m}$ long, $15 \mu \mathrm{m}$ wide; $2-3$ inner verticals, $2-3$ outer verticals, 2-3 postorbitals.

Thorax: Acrostichals 10-17, 13; dorsocentrals 6-8, 7; humerals $0-1$; prealars 1 ; scutellars 2-6, 5; halterals 5-6.

Wing (Fig. 1C): Cuneiform, 3.2-3.5, 3.4 times longer than broad; VR 1.30-1.43, 1.37; wing setation as in Fig. $1 \mathrm{C}$.
Legs (Fig. 1D): Fore tibia with $15 \mu \mathrm{m}$ long spur; mid and hind tibiae with well separated, $10-13 \mu \mathrm{m}$ and 10-14 $\mu \mathrm{m}$ long combs, mid tibial combs with 15-25, $20 \mu \mathrm{m}$ long spurs, hind tibial combs with 15-25, 20 and 13-25, $17 \mu \mathrm{m}$ long spurs. Lengths and ratios of leg segments in Table 1.

Hypopygium (Figs 1E-F): Anal tergite 76-97, $86 \mu \mathrm{m}$ long with 6-11, 8 median tergite setae; seta present on laterosternite IX; 22-32, 27 apical setae; anal point $35-45,40 \mu \mathrm{m}$ long, basally $5-10,8 \mu \mathrm{m}$ broad with well developed, high crests, anal point distally thin $2-3 \mu \mathrm{m}$ wide; spinules absent from anal point; microtrichia-free areas absent at base of anal point. Gonocoxite $63-87,76$ $\mu \mathrm{m}$ long; gonostylus 45-57, $52 \mu \mathrm{m}$ long; HR 1.37-1.58, 1.45. Superior volsella digitiform with small apical point, slightly directed towards median; setiger with 3-4 dorsal setae of which 1 is subapical and 2 are median, otherwise bare; median volsella stout, $13-18,15 \mu \mathrm{m}$ long, medially directed, stem bare, with rosette of simple and subulate, $17-25,22 \mu \mathrm{m}$ long lamellae; inferior volsella c. $53 \mu \mathrm{m}$ long, digitiform, almost straight, with several distal setae, dorsal surface with microtrichia medially.

Adult female ( $\mathrm{n}=2$, unless otherwise stated). Length 1.4-1.5 mm; wing 0.91-1.23 mm. Colour similar to male, but clearly paler (could be due to storage in alcohol).

Head: Antenna (Fig. 1G) with ultimate flagellomere 55-58 $\mu \mathrm{m}$ long, AR 0.23-0.28; frontal tubercles minute cones, 7-8 $\mu \mathrm{m}$ long; lengths of palpomeres (in $\mu \mathrm{m}$ ): 20 ; $25 ; 85 ; 80-90 ; 115-135$. Clypeus with $8-9$ setae.

Thorax: Acrostichals 14; dorsocentrals 6; humerals 3; prealars 1; scutellars 4-6; halterals 6 .

Wing: As male, except with more setae; 2.9 times longer than broad; VR 1.28-1.39.

Legs: Fore tibia with $10 \mu \mathrm{m}$ long spur; mid and hind tibiae with well separated, $10 \mu \mathrm{m}$ and $12-13 \mu \mathrm{m}$ long 


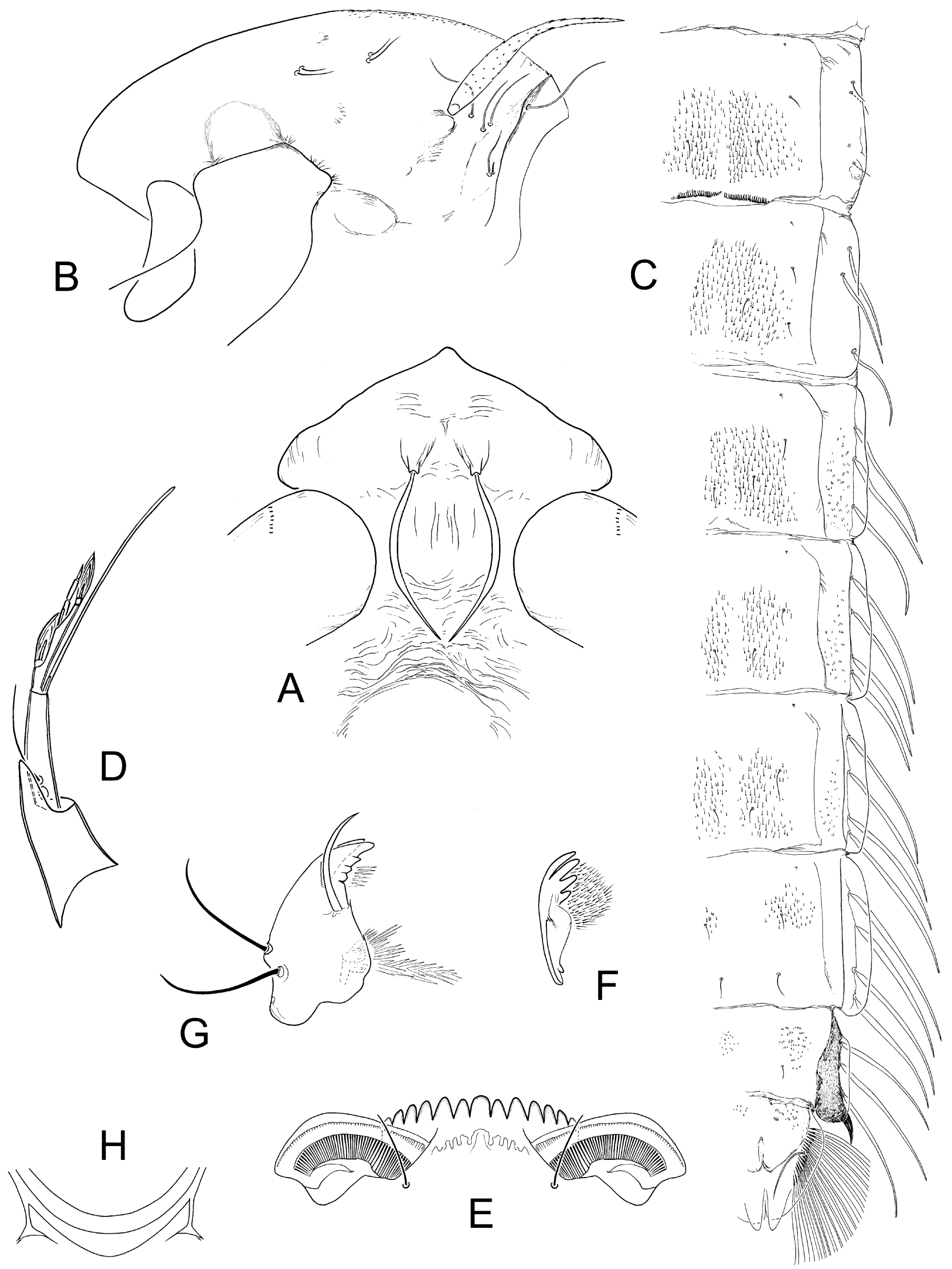

Fig. 2. Zavrelia aristata sp. n., immatures. (A-C) pupa: (A) frontal apotome; (B) thorax; (C) abdomen dorsal view. (D-H) larval head: (D) antenna; (E) mentum; $(\mathrm{F})$ premandible; $(\mathrm{G})$ mandible; $(\mathrm{H})$ postoccipital plate. 
combs, mid tibial combs each with $15 \mu \mathrm{m}$ long spurs, one hind tibial comb with $20 \mu \mathrm{m}$ long spur.

Genitalia (Fig. 1H): Tergite IX 37-45 $\mu \mathrm{m}$ long; sternite VIII with 22-26 setae; gonocoxite with 1-2 setae; gonocoxapodeme strongly curved towards median; coxosternapodeme well developed with obvious anterior and posterior lobes. Notum including rami 115-125 $\mu \mathrm{m}$ long, notum alone $60-65 \mu \mathrm{m}$ long. Seminal capsule diameter $50 \mu \mathrm{m}$ with c. $220 \mu \mathrm{m}$ long spermathecal ducts. Cercus 37-38 $\mu \mathrm{m}$ long.

Pupa ( $\mathrm{n}=3$, unless otherwise stated). Length 1.9-2.3, $2.1 \mathrm{~mm}$; abdomen 1.3-1.7, $1.5 \mathrm{~mm}$ long. Colour of pupal exuviae pale brownish with slightly darker lateral margins on abdominal segment VII-VIII.

Cephalothorax (Figs 2A-B): Cephalic tubercle well developed, 25-30, $27 \mu \mathrm{m}$ long; frontal seta taeniate, 125-140, $130 \mu \mathrm{m}$ long; pedicel sheath tubercle absent. Thoracic horn $235-275,262 \mu \mathrm{m}$ long, 15-20, $16 \mu \mathrm{m}$ wide with $5 \mu \mathrm{m}$ long chaetae scattered over almost whole horn; precorneals taeniate, arranged in triangular pattern, on obvious mound, c. 75-125, $100 \mu \mathrm{m}$ long (anterior seta slightly longer), anterior two setae placed closer together; median antepronotal taeniate c. $80 \mu \mathrm{m}$ long, 2 lateral antepronotals: 1 taeniate c. $60 \mu \mathrm{m}$ long, 1 long sensillum basiconicum; 2 pairs dorsocentrals, both $35 \mu \mathrm{m}$ long. Small area of granulation along median suture line dorsal to $\mathrm{Dc}_{1}$. Prealar tubercle not developed, wide, at most 5-10 $\mu \mathrm{m}$ long.

Abdomen (Fig. 2C): TII with a large, rectangular microspinule patch, microspinules start at level of seta D1, small microspinule-free line medioposteriorly; hook row 100-130, $117 \mu \mathrm{m}$ wide with 40-63, 52 hooks. TIII-IV with large, semi-square fields of microspinules (anterior patch margin convex), small posteromedian, oval area without armament; TV-TVI with broad, longitudinal patches of microspinules and shagreen, patches somewhat wider anteriorly and posteriorly, almost connecting anteriorly; TVII-IX with anterolateral patches of shagreen. Segment II with 2-3D, 1V, 3L setae; segment III with 3D, 1-2V, 3 taeniate L setae; segment IV with $3 \mathrm{D}, 2 \mathrm{~V}, 3$ taeniate $\mathrm{L}$ setae; segment $\mathrm{V}$ with $3 \mathrm{D}, 2 \mathrm{~V}, 3$ taeniate L setae; segment VI -VII with 2D, 3V, 4 taeniate L setae; segment VIII with $1 \mathrm{D}, 1 \mathrm{~V}, 3$ taeniate L setae; segment IX with 1D seta on anal lobe, anal fringe of 15-16 taeniate setae. 1 pair of O-setae present anteriorly on tergites II-VIII and anterolaterally on sternites II-VIII. Pleura IV-VI with fields of shagreen, often also scattered shagreen on pleura III. Posterolateral spur on segment VIII simple.

Larva ( $\mathrm{n}=5$, unless otherwise stated). Length c. 2.0 $\mathrm{mm}$, case c. $2.5 \mathrm{~mm}$ long. Head capsule pale brown, somewhat darker postoccipital rim and teeth on mandible and mentum. Live specimens not examined.

Head (Figs 2D-H): Length c. $235 \mu \mathrm{m}$, width c. 120 $\mu \mathrm{m}$; AR 0.80-0.96, 0.91; antennal pedestal 65-67 $\mu \mathrm{m}$ long with well developed, 25-32, $29 \mu \mathrm{m}$ digitiform spur; antenna (Fig. 2D) with all segments well sclerotized, segment lengths (in $\mu \mathrm{m}$ ): $65-70,67 ; 39-50,42 ; 12-20,15$; $10-12,10 ; 5-7,6$; segment three inserted subapically on segment two; AAR 0.96-1.00, 0.98. Antennal blade 125-150, 130 (3) $\mu \mathrm{m}$ long, pale, reaching well beyond tip of distal Lauterborn organ; peg of antennal segment two placed subapically on segment. Lauterborn organs 17-22, $20 \mu \mathrm{m}$ long; proximal organ positioned $1 / 3$ along length of antennal segment two on a $5 \mu \mathrm{m}$ long pedicel, apical organ on 7-8 $\mu \mathrm{m}$ long pedicel; S3 and chaetulae simple; labral lamella with c. 26 teeth. Mentum (Fig. 2E) with all lateral teeth similar in size, lateralmost teeth slightly smaller, set an equal distance apart; ventromental plates medially reaching median margin of third lateral tooth of mentum, MVR 1.15-1.44, 1.24; premandible in Fig. 2F; mandible (Fig. 2G) with pecten mandibularis slightly convex, seta subdentalis 40-45, 42 (4) $\mu \mathrm{m}$ long; postoccipital plate (Fig. 2H) moderately broad.

Body: Hind parapod with 16 simple hooks; L2 apparently simple; two pairs of anal tubules c. 50-75, $64 \mu \mathrm{m}$ long; supraanal seta strong, 200-250, $225 \mu \mathrm{m}$ long; procercus c. $30 \mu \mathrm{m}$ long with 2 short (c. $150 \mu \mathrm{m}$ ) and 4 long (c. $550 \mu \mathrm{m}$ ) anal setae.

Material. Holotype: 1 LPô (USNM) USA, OH: Portage Co., West Bronch State Park, spring nr source, 21.v.1986, emerged 25.v.1989, M.J. Bolton. 35 paratypes: 1 LP $\widehat{o}, 1$ LP +1 L (USNM) as Holotype except emergence dates; 20, $1 \mathrm{LP}, 1 \mathrm{~L}$ (NTNU) as Holotype except 19.v.1990, 5.iv.1986; USA, GA: 3ô, 3L (USNM) Hall Co., Pitts Creek nr Oliver Mill Rd., unnamed stream, 1.vii.1998, 10.viii.1998, 31.viii.1998, B.A. Caldwell; 1 L (USNM) Fulton Co., seep area at Douglas and Trimble Rds., 20.ii.1986, B.A. Caldwell; 1 LP 9 (NTNU) White Co., Hwy 11 to Vogel State Park, small waterfall in unnamed stream, 8.iii.1981, B.A. Caldwell; USA, NC: 1 L (USNM) Macon Co., Coweeta Hydr. Lab., seep at entrance, 26.iv.1991, B.A. Caldwell; 10 (USNM) Haywood Co., BLRI, Soco Gap, sweep net at seep area, $1311 \mathrm{~m}$ a.s.l., 13.vi.1991, C.R. Parker; $1 \delta^{\hat{t}}$ (PLH) Swain Co., Macon Co., Hiawasee River, 10.iii.1990, P. Hudson; USA, FL: 3 ๙ , 1 ㅇ (NTNU) Gadsden Co., Florida A \& M University farm, stream $\mathrm{nr}$ ravine head, $30^{\circ} 36^{\prime} 27^{\prime \prime} \mathrm{N}$ 84³6'50"W, 8.ii.1999, 10.iv.1999, A.K. Rasmussen; USA, VA: 10 (UMSP) Giles Co., Goldbond, 8.v.1969, F.V. Battle; USA, SC: 10 (PLH), 1 ㅇ, $2 \hat{0}$ (UMSP) Pickens Co., Clemson Univ., Issaqueena Forest, 1.iii.1981, 3.iii.1981, 29.iii.1981, P.L. Hudson; 2 o (UMSP) Oconee Co., Jocassee Overlook, seepage area, 19.ix.1978; $1 \delta^{\hat{0}}$ (UMSP) Oconee Co., Salem, Jocassee, 15.x.1973, P.L. Hudson; 10 (UMSP) Oconee Co., Chattooga River, East Fork, National Fish Hatchery, 25.v.1981, P.L. Hudson; USA, NY: 20 (USNM) Allegany State Park, Sphagnum bog, 3.vi.1963, W.W. Wirth; $1 \delta^{\dagger}$ as previous except stream margin 28.v.-3.vi.1963. Canada: $10^{\widehat{t}}$ (CNC \#CH7259) New Brunswick: Kouchibouguac National Park, 11.vii.1978, D. Oliver \& M. Russel.

Etymology. "aristata", Latin adjective meaning bearded, referring to the setose anal tergite of the male hypopygium.

Remarks. Zavrelia aristata is very similar to Z. hudsoni from Sevier Co., Tennessee, described below, but can be separated from this species by the smaller body size and higher AR of the adult male, the shorter cerci of the adult female, the presence of 4 taeniate lateral setae on the pupal abdominal segment $\mathrm{V}$ (as opposed to 3) and the longer antennal segment 1, longer antennal blade and lower AAR of the larva. The species is also similar to $Z$. elenae from the Russian Far East in the pupal stage and can only be separated by the presence of parallel micro- 


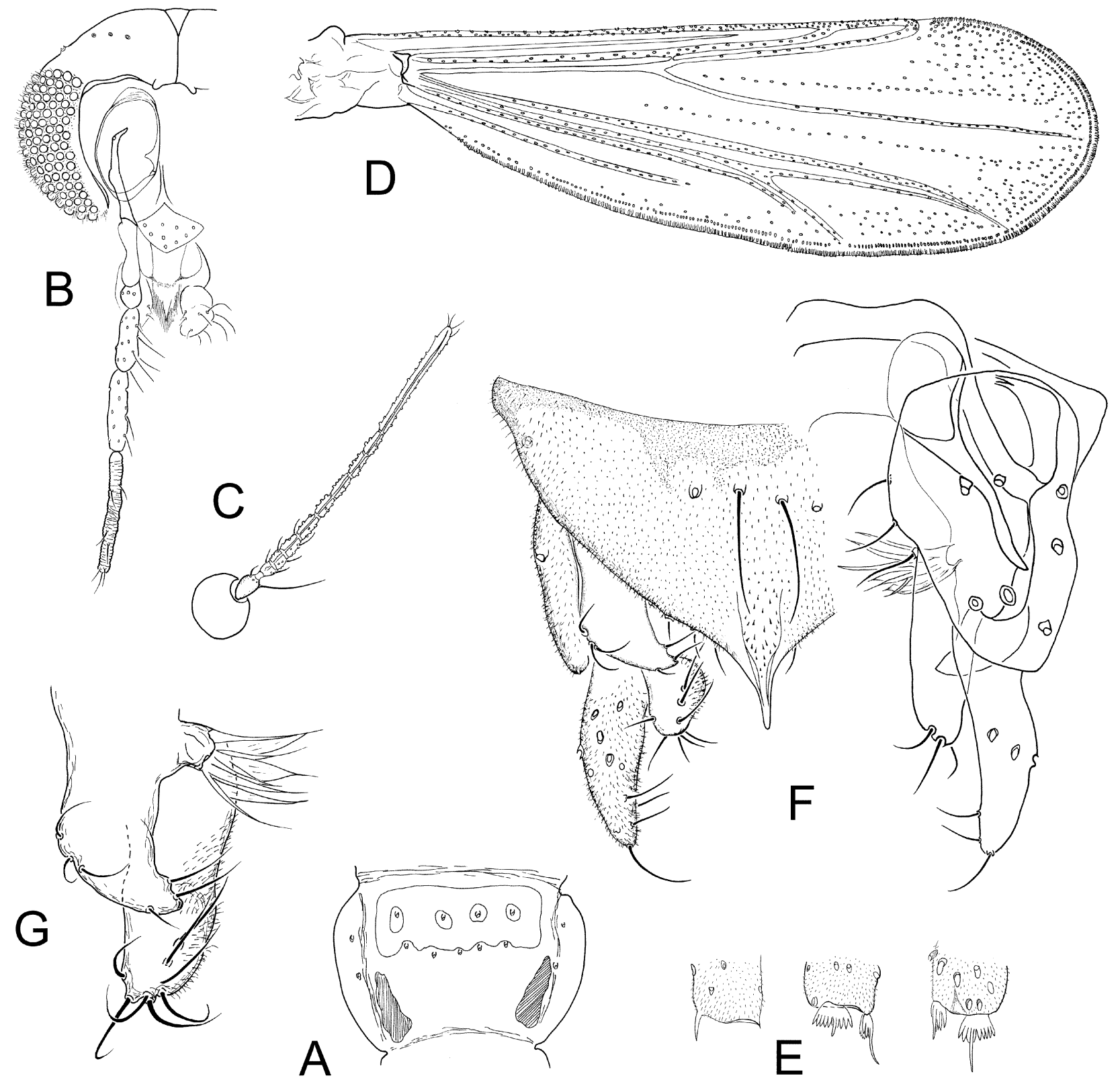

Fig. 3. Zavrelia casasi sp. n., male imago. (A) abdominal tergite VII; (B) head; (C) antenna; (D) wing; (E) apex of fore, mid and hind tibia; (F) hypopygium, dorsal and ventral view; $(\mathrm{G})$ superior, median and inferior volsella.

spinule patches on TV-VI and the absence of shagreen on pleura III.

Zavrelia aristata has been found in or near springs, spring brooks, small streams, bogs and seepages from Florida in the south to New Brunswick in the north of North America. The larvae build straight cases, slightly tapered towards posterior, of coarse sand grains and a few bits of detritus.

\section{Zavrelia casasi sp. $\mathbf{n}$.}

\section{Diagnostic characters}

Zavrelia casasi can be separated from other Zavrelia species by the following combination of characters. Adult male length c. $1.5 \mathrm{~mm}$; AR about 0.6; frontal tubercle small, conical; anal point with c. 30 small spinules between well developed crests; c. 4 strong median tergite setae placed at some distance from anal point base; median volsella short, stout, with simple and subulate lamellae. Pupa with granulose anterior cephalothorax; moderately developed cephalic tubercles; thoracic horn comparatively short and thick with numerous small chaetae scattered along whole length; anteriormost dorsocentral long and taeniate, remaining dorsocentrals considerably shorter and simple; microspinule patches on tergite II-V large, covering most of tergite; microspinule patches on tergite VI two broad longitudinal rows; pleura II-VI with shagreen; anal lobe with c. 20 taeniate setae in a fringe.

\section{Description}

Adult male ( $\mathrm{n}=3$, unless otherwise stated). Length 1.4-1.6, $1.5 \mathrm{~mm}$; wing length $0.90-1.10$. 


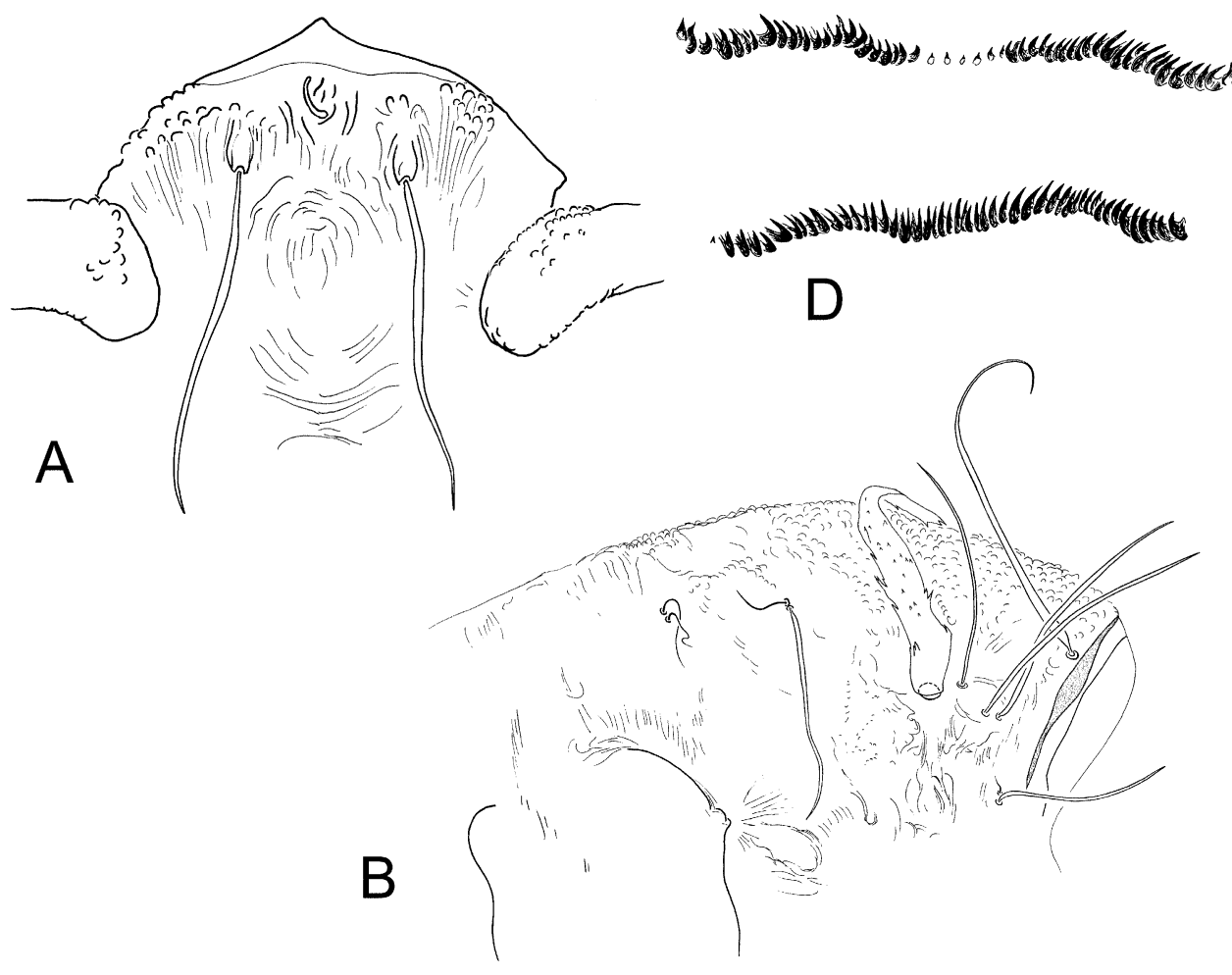

Fig. 4. Zavrelia casasi sp. n., pupa. (A) frontal apotome; (B) thorax; (C) abdomen dorsal view; (D) variation in hook row.

Colour: Thorax brown with pale scutellum and halteres; abdomen light brown, tergite 7 with posterior transverse white band flanked by dark brown marks (Fig. 3A); head and eyes dark brown; legs and palpomeres pale yellow.

Head (Fig. 3B): Frontal tubercle small, conical, 5-10, 8 $\mu \mathrm{m}$ long; Antenna (Fig. 3C) with AR 0.59 (2); lengths of palpomeres: $20-25 ; 25-30 ; 65-70 ; 75-85$ (2); 120 (1). Clypeus about $35 \mu \mathrm{m}$ long with 9-10 setae; tentorium c. $100 \mu \mathrm{m}$ long, $13 \mu \mathrm{m}$ wide; 0-2 inner verticals, 1-2 outer verticals, 2 postorbitals.

Thorax: Acrostichals 11-12 (2); dorsocentrals 6-8; humerals 1-2; prealars 1; scutellars 2-5, 4; halterals 6 (2).

Wing (Fig. 3D): Cuneiform, 2.7-3.1 times longer than broad; VR 1.39-1.47, 1.43; wing setation as in Fig. 3D.

Legs (Fig. 3E): Fore tibia with $15 \mu \mathrm{m}$ long spur; mid and hind tibiae with well separated, $10 \mu \mathrm{m}$ long combs, one mid tibial comb with $20 \mu \mathrm{m}$ long spur, other with 10-12 $\mu \mathrm{m}$ long spur; one hind tibial comb with 20-25, 22 $\mu \mathrm{m}$ long spur, other with $12 \mu \mathrm{m}$ long spur. Lengths and ratios of leg segments in Table 1.

Hypopygium (Figs 3F-G): Anal tergite 75-78, $76 \mu \mathrm{m}$ long with 4-5 median tergite setae; laterosternite IX usually with seta; 16-30, 24 apical setae; anal point 27-35 $\mu \mathrm{m}$ long, basally $8-10 \mu \mathrm{m}$ broad with well developed crests, anal point distally thin $2-3 \mu \mathrm{m}$ wide; $25-40,32$ small spinules between anal point crests; microtrichia-free areas absent at base of anal point. Gonocoxite 70-74, 71 $\mu \mathrm{m}$ long; gonostylus 42-50, $47 \mu \mathrm{m}$ long; HR 1.40-1.67, 1.52. Superior volsella triangular, apex pointed and medially directed, with $3-4$ dorsal setae of which 1 is subapi- cal, and 2 median setae on setiger, otherwise bare; median volsella (Fig. 3G) stout, 8-10, $9 \mu \mathrm{m}$ long, medially directed, stem bare, with rosette of simple and subulate, 12-15, $13 \mu \mathrm{m}$ long lamellae; inferior volsella $\mathrm{c}$. 45-50 $\mu \mathrm{m}$ long, digitiform, almost straight, with several distal setae, dorsal surface with microtrichia medially.

Pupa ( $\mathrm{n}=5$, unless otherwise stated). Length 1.8-2.4, $2.2 \mathrm{~mm}$; abdomen 1.4-1.8, $1.6 \mathrm{~mm}$ long. Colour of exuviae: cephalothorax light brown, abdomen transparent with slightly darker lateral margins on abdominal segment VII-VIII, faint pigmentation on anal lobe.

Cephalothorax (Figs 4A-B): Cephalic tubercle moderately developed, 10-20, $17 \mu \mathrm{m}$ long; frontal seta taeniate, 100-150, $125 \mu \mathrm{m}$ long; pedicel sheath tubercle absent. Frontal apotome (Fig. 4A) partly coarsely granulose. Thoracic horn 175-270, $233 \mu \mathrm{m}$ long, 20-30, $27 \mu \mathrm{m}$ wide with 10-12 $\mu \mathrm{m}$ long chaetae scattered on almost whole horn; precorneals taeniate, arranged in triangular pattern, on obvious mound, c. 100-150 $\mu \mathrm{m}$ long, anterior two setae placed closer together; median antepronotal taeniate 

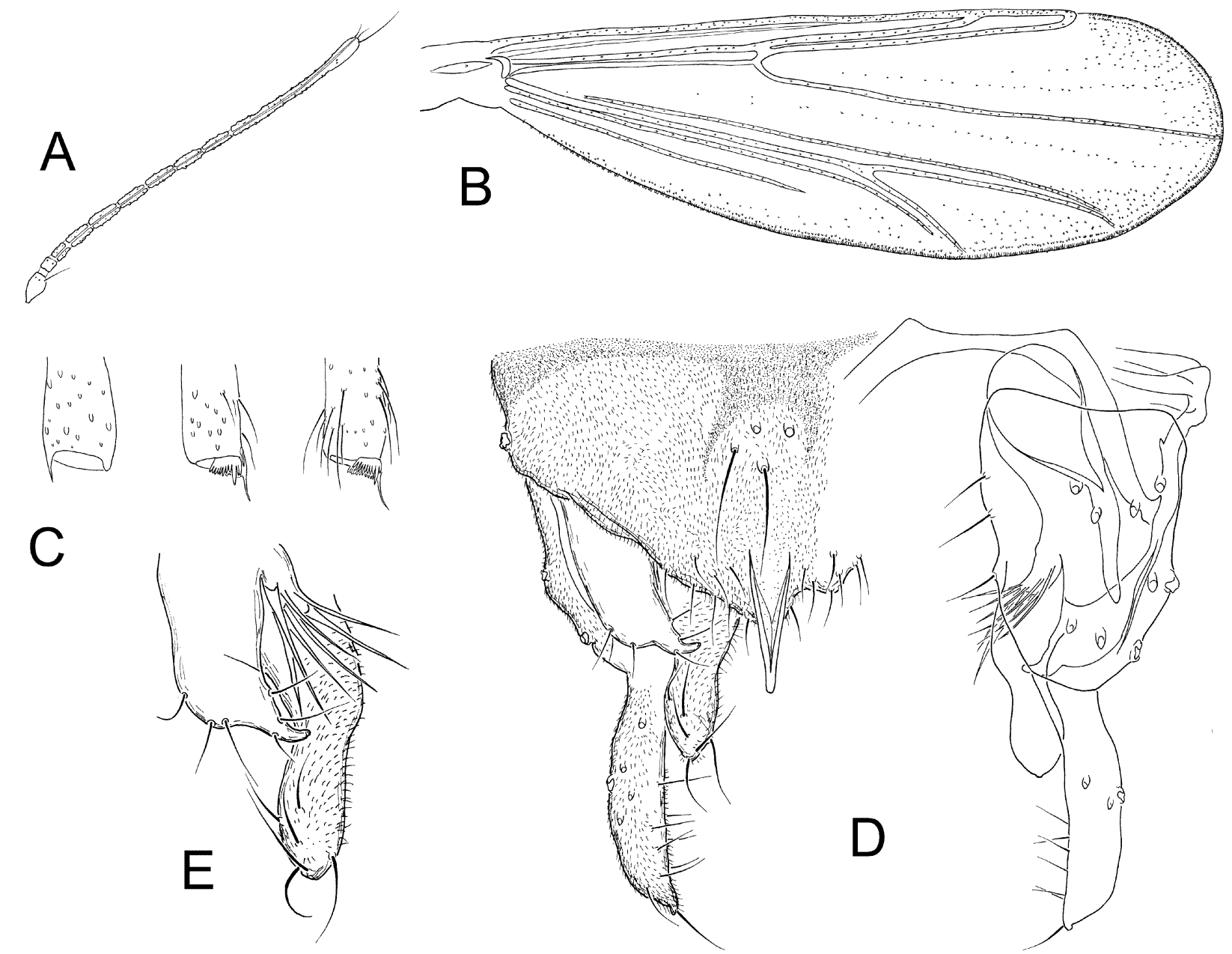

Fig. 5. Zavrelia clinovosella Guo \& Wang, male imago. (A) antenna; (B) wing; (C) apex of fore, mid and hind tibia; (D) hypopygium, dorsal and ventral view; (E) superior, median and inferior volsella.

c. $250 \mu \mathrm{m}$ long, 2 lateral antepronotals: 1 taeniate c. 100 $\mu \mathrm{m}$ long, 1 long sensillum basiconicum; 2 pairs dorsocentrals, anteriormost seta taeniate c. $180 \mu \mathrm{m}$ long, rest 35 $\mu \mathrm{m}$ long. Thorax heavily wrinkled and coarsely granulated anterodorsally (Fig. 4B). Prealar tubercle not developed, wide, at most 5-10 $\mu \mathrm{m}$ long.

Abdomen (Figs 4C-D): TII with rectangular microspinule patch, microspinules start at level of seta D1, small microspinule-free line in medioposteriorly; hook row (Fig. 4D) 100-150, $125 \mu \mathrm{m}$ wide, sometimes almost broken, with 52-80, 61 hooks. TIII-V with large, semisquare fields of microspinules (anterior patch margin convex), small posteromedian, oval area without armament, patch on TV slightly smaller; TVI with separated, broad, longitudinal patch of microspinules and shagreen; TVII-IX with anterolateral patches of shagreen. Segment II with $2 \mathrm{D}, 2 \mathrm{~V}, 3 \mathrm{~L}$ setae; segment III with $2-3 \mathrm{D}, 1-2 \mathrm{~V}$, 0-1 L setae, 2-3 taeniate $\mathrm{L}$ setae; segment IV with $3 \mathrm{D}$, 2V, 0-1 L setae, 2-3 taeniate $\mathrm{L}$ setae; segment $\mathrm{V}$ with 2-3D, 2V, 3 taeniate L setae; segment VI -VII with 2-3D, 3V , 4 taeniate L setae; segment VIII with $1 \mathrm{D}, 1 \mathrm{~V}$, 3 taeniate L setae; segment IX with 1D seta on anal lobe, 15-23, 20 taeniate setae in anal fringe. 1 pair of O-setae present anteriorly on tergites II-VIII and anterolaterally on sternites II-VIII. Pleura III-VI with fields of shagreen. Posterolateral spur on segment VIII simple.

Adult female and larva unknown.

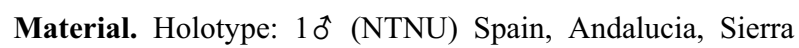
Nevada, upstream village Lanjarón, nr. Refugio Tello Lanjarón A, N36.970 ${ }^{\circ}$ W3.456 ${ }^{\circ}, 1500 \mathrm{~m}$ a.s.1., 24.viii.1987, J. Casas. 9 paratypes (NTNU): $2 \hat{\delta}, 3$ pex as holotype; 1 P (\$) Spain, Andalucia, Sierra Nevada, nr. Prado Llano, "Monachil-1", $37.089^{\circ} \mathrm{N}, 3.398^{\circ} \mathrm{W}, 2100 \mathrm{~m}$ a.s.1., 15.x.1987, J. Casas; 3 pex Spain, Andalucia, Sierra Nevada, Rio Trevélez, upstream village Trevélez, "Treveléz-1", $37.00288^{\circ} \mathrm{N}, 3.26174^{\circ} \mathrm{W}, 1438 \mathrm{~m}$ a.s.1., 14.v.1986, J. Casas.

Etymology. The species is named after our colleague Jesús Casas who collected the type material.

Remarks. The pupa described above is tentatively associated with the adult males that were found at the same place and date at Lanjarón, so we regard the association to be very likely. There was only material of one female available for examination and this specimen (a pharate adult) lacked abdomen and thorax. Thus, this material was inappropriate for description.

The adult of Zavrelia casasi is morphologically closest to Z. tusimatijea from the Tsushima Islands, but can easily be separated from this species by its smaller size, 
lower AR and single-lobed superior volsella. Immatures of $Z$. tusimatijea are unknown.

\section{Zavrelia clinovolsella Guo \& Wang, 2004}

Zavrelia clinovolsella Guo \& Wang, 2004: 186.

Diagnostic characters

Zavrelia clinovolsella can be separated from other Zavrelia species by the following combination of characters. Length of adult male c. $1.8 \mathrm{~mm}$; AR about 0.59 ; frontal tubercle small, conical; anal point without spinules but with a few microtrichia between long crests; c. 4 strong median setae on tergite placed at some distance from anal point base; superior volsella with abruptly tapered, sickle-shaped setiger.

\section{Description}

Adult male $(\mathrm{n}=1)$. Length $1.8 \mathrm{~mm}$; wing length 1.19 mm.

Colour: Body and head ground colour brown, dark pedicels, scutal stripes, postnotum and median anepisternum. Scutellum paler, eyes blackish.

Head: Frontal tubercle weakly developed, $8 \mu \mathrm{m}$ long; antenna (Fig. 5A) with AR 0.59; lengths of palpomeres (in $\mu \mathrm{m}$ ): $20,25,65,90,140$. Clypeus about $45 \mu \mathrm{m}$ long with 7 setae; tentorium c. $100 \mu \mathrm{m}$ long, $15 \mu \mathrm{m}$ wide; 2 inner verticals, 3 outer verticals, 1 post orbital.

Thorax: Acrostichals 10; dorsocentrals 6; humerals 2; prealars 1; scutellars 3 .

Wing (Fig. 5B): cuneiform, 2.8 times longer than broad; VR 1.47; wing setation as in Fig. 5B.

Legs (Fig. 5C): Fore tibia with $18 \mu \mathrm{m}$ long spur; mid and hind tibiae with well separated, 12 and $10 \mu \mathrm{m}$ long combs, mid tibial combs with 25 and $15 \mu \mathrm{m}$ long spurs, hind tibial combs with 30 and $13 \mu \mathrm{m}$ long spurs. Lengths and ratios of leg segments in Table 1.

Hypopygium (Figs 5D-E): Anal tergite $137 \mu \mathrm{m}$ long with 4 median tergite setae; seta present on laterosternite IX; 16 apical setae; anal point $35 \mu \mathrm{m}$ long, basally $10 \mu \mathrm{m}$ broad with well developed, high crests, anal point distally thin $3 \mu \mathrm{m}$ wide; spinules absent but microtrichia present between crests on anal point; microtrichia-free areas at anal point base absent. Gonocoxite $80 \mu \mathrm{m}$ long; gonostylus $57 \mu \mathrm{m}$ long; HR 1.40. Superior volsella with broad base, setiger abruptly tapered and sickle-shaped towards medially directed apex, 4 dorsal and 2 median setae on setiger, otherwise bare; median volsella stout, $8 \mu \mathrm{m}$ long, medially directed, stem bare, with rosette of simple and subulate, $25 \mu \mathrm{m}$ long lamellae; inferior volsella c. $43 \mu \mathrm{m}$ long, angled median margin, with several distal setae, dorsal surface almost covered with microtrichia.

Adult female, pupa and larva unknown.

Material. Holotype of (NKUM No. 11253) China, Yunnan Province, Dali County, Diancangshan Mt., Qingbijiang River, LT, $2500 \mathrm{~m}$ a.s.1, 23.v.1996, X. Wang.

Remarks. Zavrelia clinovolsella is recorded only by a river in the Diancan Mountains, China (Guo \& Wang, 2004).

\section{Zavrelia hudsoni sp. n.}

\section{Diagnostic characters}

Zavrelia hudsoni can be separated from other Zavrelia species by the following combination of characters. Length of adult male c. $2.0 \mathrm{~mm}$; AR about 0.75 ; frontal tubercle small, conical; anal point with microtrichia, but without spinules between long crests; 11-12 strong median tergite setae placed at some distance from anal point base; superior volsella digitiform with small apical point, 5 dorsolateral and 2 median setae on setiger; median volsella short, stout, with simple and subulate lamellae. Adult female with AR c. 0.22; vaginal floor absent, lateral margin of vagina without ventral extension; spermathecal duct far longer than notum and rami combined, c. $200 \mu \mathrm{m}$ long; notum considerable longer than rami; diameter of seminal capsule moderately long, shorter than length of notum; cercus comparatively large, $50 \mu \mathrm{m}$ long. Pupa with well developed conical cephalic tubercle; thoracic horn long with numerous small chaetae scattered along almost whole length; thorax smooth except for small area of granulation along scutal suture and posterior to thoracic horn; anterior dorsocentrals as long as posterior dorsocentrals; microspinule patches on tergites II-IV large, semi-square, starting anterior to seta D1; microspinule patches on tergites $\mathrm{V}$ and $\mathrm{VI}$ in two large, $\pi$-shaped; pleura IV-VI with shagreen; segment V with 3 taeniate lateral setae; anal lobe with 16-19 taeniate setae in fringe. Larva with well developed, (c. 25 $\mu \mathrm{m}$ long), digitiform spur on antennal pedestal; AR 0.89 ; antennal segment 1 c. $55 \mu \mathrm{m}$ long; distal Lauterborn organ on $7 \mu \mathrm{m}$ long pedicel, basal Lauterborn organ on 5 $\mu \mathrm{m}$ pedicel $1 / 4$ along length of antennal segment 2 ; S3 simple.

\section{Description}

Adult male $(\mathrm{n}=2$, unless otherwise stated). Length 1.9-2.1 mm; wing length 1.41 (1).

Colour: Body and head ground colour light yellowishbrown, darker antennal pedicel, scutal stripes, median anepisternum, epimeron II, preepisternum and postnotum. Scutellum, halteres, legs and palpomeres pale yellow, eyes dark brown.

Head (Fig. 6A, B): Frontal tubercle small, $11 \mu \mathrm{m}$ long; antennae (Fig. 6C) with AR $0.75-0.77$; lengths of palpomeres (in $\mu \mathrm{m}, \mathrm{n}=1$ ): $25 ; 30 ; 125 ; 110 ; 150$. Clypeus about $35 \mu \mathrm{m}$ long with 11 setae; tentorium c. $100 \mu \mathrm{m}$ long, $15 \mu \mathrm{m}$ wide; 3 inner verticals, 3 outer verticals, 2 postorbitals.

Thorax: Acrostichals 14-17; dorsocentrals 6; humerals 3; prealars 1; scutellars 6; halterals 6 .

Wing ( $\mathrm{n}=1$, Fig. 6D): Cuneiform, 3.4 times longer than broad; VR 1.38; wing setation as in Fig. 6D.

Legs (Fig. 6E): Fore tibia with $15 \mu \mathrm{m}$ long spur; mid and hind tibiae with well separated, 10-12 $\mu \mathrm{m}$ long combs, mid tibial combs with 20-25 $\mu \mathrm{m}$ long spurs, hind tibial combs with $20 \mu \mathrm{m}$ long spurs. Lengths and ratios of leg segments in Table 1.

Hypopygium (Figs 6F, G): Anal tergite 100-105 $\mu \mathrm{m}$ long with 11-12 median tergite setae; seta present on 


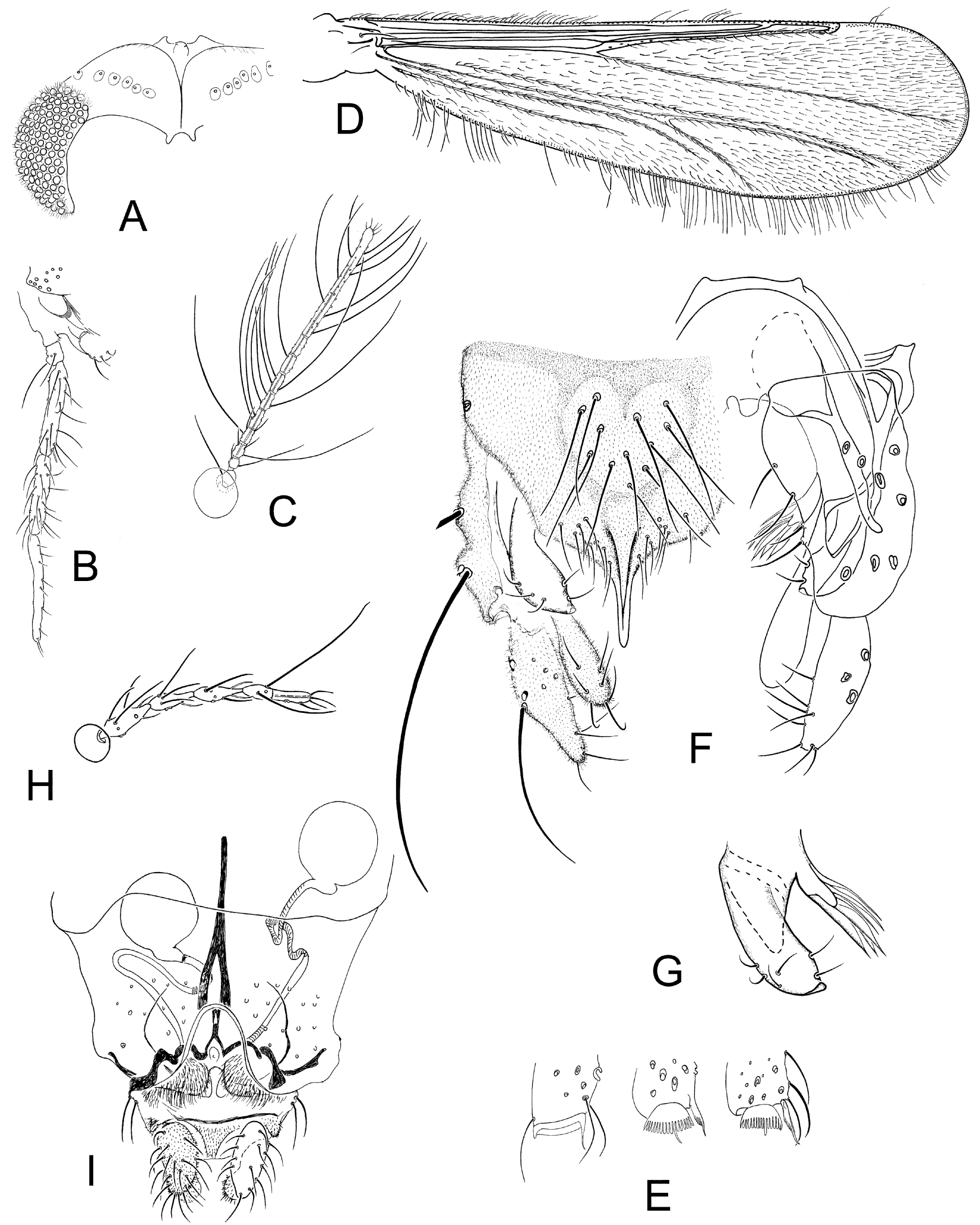

Fig. 6. Zavrelia hudsoni sp. n., imagines. (A-G) male: (A) dorsal part of head; (B) maxillary palp; (C) antenna; (D) wing; (E) apex of fore, mid and hind tibia; $(F)$ hypopygium, dorsal and ventral view; $(G)$ superior, median and inferior volsella. $(\mathrm{H}-\mathrm{I}) \mathrm{female}$ ( $\mathrm{H})$ antenna; (I) genitalia.

laterosternite IX; 28-40 apical setae; anal point 37-45 $\mu \mathrm{m}$ long, basally 6-7 $\mu \mathrm{m}$ broad with well developed, high crests, anal point distally thin 2-3 $\mu \mathrm{m}$ wide; spinules absent on anal point; microtrichia-free areas absent at base of anal point. Gonocoxite 77-87 $\mu \mathrm{m}$ long; gonostylus $50 \mu \mathrm{m}$ long; HR 1.54-1.74. Superior volsella (Fig. 6G) digitiform with small apical point, slightly directed towards median, with 5 dorsolateral setae of which 1 is 


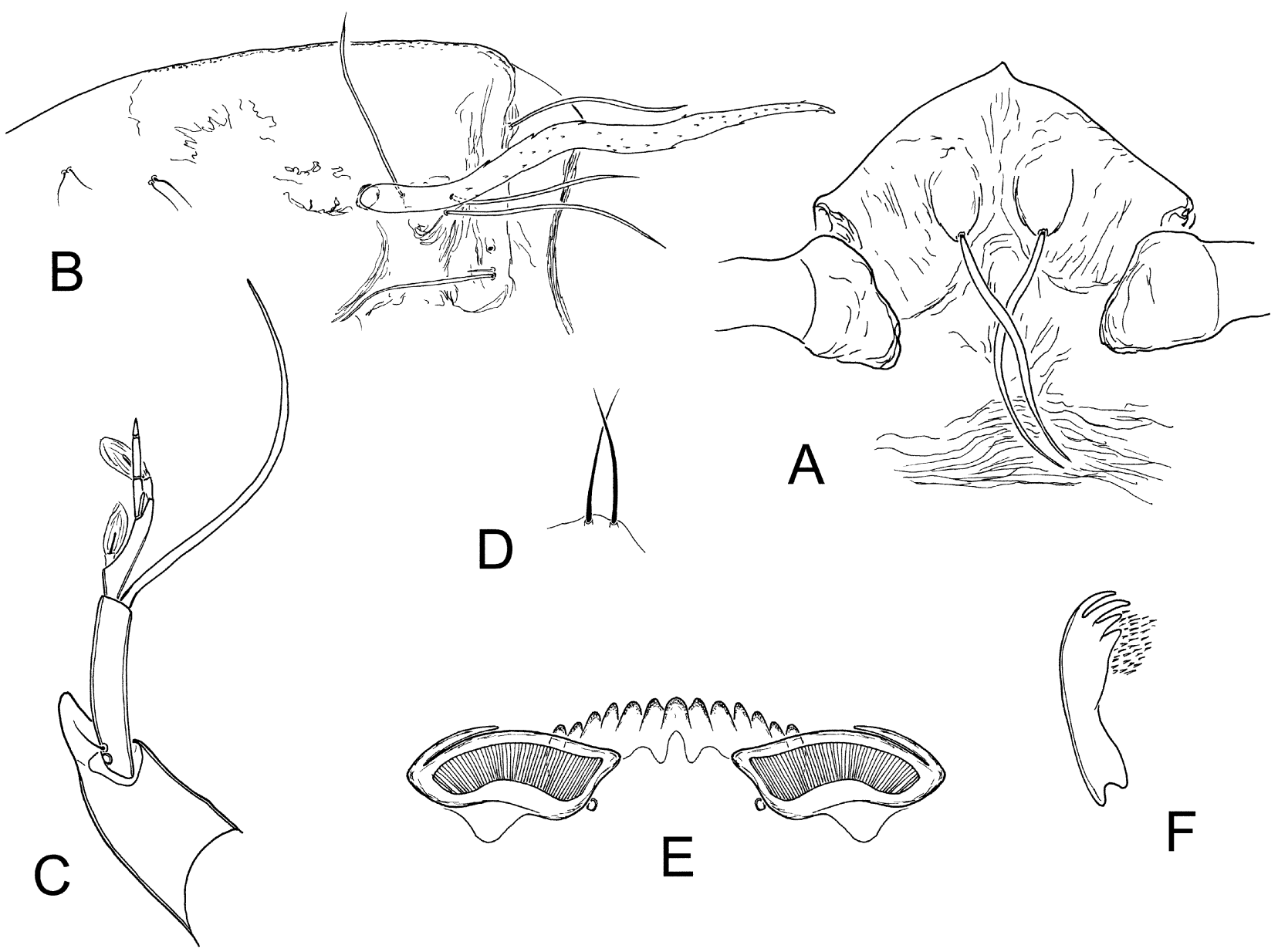

Fig. 7. Zavrelia hudsoni sp. n., immatures. (A-B) pupa: (A) frontal apotome; (B) thorax. (C-F) larval head: (C) antenna; (D) clypal setae S3; (E) mentum; (F) premandible.

subapical, and 2 median setae on setiger, otherwise bare; median volsella stout, 16-17 $\mu \mathrm{m}$ long, medially directed, stem bare, with rosette of simple and subulate, $25 \mu \mathrm{m}$ long lamellae; inferior volsella c. 55-67 $\mu \mathrm{m}$ long, digitiform, almost straight, with several distal setae, dorsal surface with microtrichia medially.

Adult female $(\mathrm{n}=1)$. Length $1.5 \mathrm{~mm}$; wing $1.01 \mathrm{~mm}$. Colour similar to male, but clearly paler (could be due to storage in alcohol).

Head: Antennae (Fig. 6H) with ultimate flagellomere $50 \mu \mathrm{m}$ long, AR 0.22; frontal tubercles minute cones, 5 $\mu \mathrm{m}$ long; lengths of palpomeres (in $\mu \mathrm{m}$ ): $20 ; 25 ; 90 ; 85$; 130. Clypeus c. $25 \mu \mathrm{m}$ long with 9 setae.

Thorax: Acrostichals 14; dorsocentrals 6; humerals 1; prealars 1; scutellars 6; halterals 5 .

Wing: as male, except with more setae; 3.1 times longer than broad; VR not measurable.

Legs: Fore tibia with $10 \mu \mathrm{m}$ long spur; mid and hind tibiae with well separated, $10 \mu \mathrm{m}$ and $12 \mu \mathrm{m}$ long combs, each with 15 and $20 \mu \mathrm{m}$ long spurs.

Genitalia (Fig. 6I): Tergite IX $37 \mu \mathrm{m}$ long; sternite VIII with 28 setae; gonocoxite with 2 setae; gonocoxapodeme slightly curved towards median; coxosternapodeme well developed with obvious anterior and posterior lobes. Notum including rami $113 \mu \mathrm{m}$ long, notum alone $70 \mu \mathrm{m}$ long. Seminal capsule diameter $47 \mu \mathrm{m}$ with c. $200 \mu \mathrm{m}$ long spermathecal duct. Cercus $50 \mu \mathrm{m}$ long.

Pupa ( $\mathrm{n}=2$, unless otherwise stated). Length 1.9-2.3 $\mathrm{mm}$; abdomen 1.4-1.7 mm long. Colour of pupal exuviae pale brownish with slightly darker lateral margins on abdominal segment VII-VIII.

Cephalothorax (Figs 7A-B): Cephalic tubercle well developed, 25-30 $\mu \mathrm{m}$ long; frontal seta taeniate, $130 \mu \mathrm{m}$ long; pedicel sheath tubercle absent. Thoracic horn 325 (1) $\mu \mathrm{m}$ long, 30 (1) $\mu \mathrm{m}$ wide with $5 \mu \mathrm{m}$ long chaetae scattered over almost the whole horn; precorneals taeniate, arranged in triangular pattern, on obvious mound, c. 110-150 $\mu \mathrm{m}$ long (anterior seta slightly longer), anterior two setae placed closer together; median antepronotal taeniate c. $110 \mu \mathrm{m}$ long, 2 lateral antepronotals: 1 taeniate c. $110 \mu \mathrm{m}$ long, 1 long sensillum basiconicum; 2 pairs dorsocentrals, both $35 \mu \mathrm{m}$ long. Small area of granulation along median suture line dorsal to $\mathrm{Dc}_{1}$. Prealar tubercle not developed, wide, at most 5-10 $\mu \mathrm{m}$ long.

Abdomen (not drawn due to distorted specimen): TII with a large, rectangular microspinule patch, microspinules start anterior to seta D1, small microspinule-free line in medioposteriorly; hook row 100-112 $\mu \mathrm{m}$ wide with 47 hooks. TIII-IV with large, semi-square fields of microspinules (anterior patch margin convex), small pos- 
teromedian, oval area without armament; TV-TVI with broad, $\pi$-shaped patches of microspinules and shagreen; TVII-IX with anterolateral patches of shagreen. Segment II with $2 \mathrm{D}, 1 \mathrm{~V}, 3 \mathrm{~L}$ setae; segment III with $3 \mathrm{D}, 2 \mathrm{~V}, 3$ taeniate L setae; segment IV with $3 \mathrm{D}, 2 \mathrm{~V}, 3$ taeniate $\mathrm{L}$ setae; segment $\mathrm{V}$ with $3 \mathrm{D}, 2 \mathrm{~V}, 3$ taeniate $\mathrm{L}$ setae; segment VI-VII with 2D, 3V, 4 taeniate L setae; segment VIII with $1 \mathrm{D}, 1 \mathrm{~V}, 3$ taeniate L setae; segment IX with 1D seta on anal lobe, 16-19 taeniate setae in anal fringe. 1 pair of O-setae present anteriorly on tergites II-VIII and anterolaterally on sternites II-VIII. Pleura IV-VI with fields of shagreen. Posterolateral spur on segment VIII simple.

Larva $(n=1)$. Length not measurable, case not examined. Head capsule pale brown, somewhat darker postoccipital rim and teeth on mandible and mentum. Live specimens not examined.

Head (Figs 7C-F): Length c. $250 \mu \mathrm{m}$, width c. $150 \mu \mathrm{m}$; AR 0.89; antennal pedestal $67 \mu \mathrm{m}$ long with well developed, $25 \mu \mathrm{m}$ digitiform spur; antenna (Fig. 7C) with all segments well sclerotized, segment lengths (in $\mu \mathrm{m}$ ): 55 ; $35 ; 12 ; 10 ; 5$; segment three inserted subapically on segment two; AAR 1.21. Antennal blade $115 \mu \mathrm{m}$ long, pale, reaching well beyond tip of distal Lauterborn organ; peg of antennal segment two placed subapically on segment. Lauterborn organs $17 \mu \mathrm{m}$ long; proximal organ positioned $1 / 4$ along length of antennal segment two on a 5 $\mu \mathrm{m}$ long pedicel, apical organ on $7 \mu \mathrm{m}$ long pedicel; S3 (Fig. 7D) and chaetulae simple; labral lamella with 26 teeth. Mentum (Fig. 7E) with all lateral teeth similar in size and set an equal distance apart; ventromental plates medially just reaching second lateral tooth of mentum, MVR 1.33; premandible in Fig. 7F; mandible with pecten mandibularis slightly convex, seta subdentalis $43 \mu \mathrm{m}$ long; postoccipital plate fragmented, but appears comparatively narrow.

Body: Hind parapod with 18 simple hooks; L2 apparently simple; two pairs of anal tubules, not measurable; supraanal seta strong, $225 \mu \mathrm{m}$ long; procercus c. $30 \mu \mathrm{m}$ long with 2 short (c. $150 \mu \mathrm{m}$ long) and 4 long (c. $600 \mu \mathrm{m}$ long) anal setae.

Material. Holotype: $1 \delta^{\hat{}}$ (UMSP) USA, TN: Sevier Co., RT 441, 12 Mi SE Gatlinburg, small stream/spring, 10.vi.1983, P. L. Hudson. 2 paratypes: 1 P $\widehat{0}$ (NTNU), 1 LP $q$ (UMSP) as holotype except spring 12 Mi SE Gatlinburg, 4.v.1980.

Etymology. The species is named after our colleague Patrick L. Hudson who collected the type material and has lent us material of many tanytarsine species for comparison and description.

Remarks. There is an additional unmacerated female with associated pupal skin from the type locality at the UMSP, which is very similar to Zavrelia hudsoni. However, this specimen is not included in the above description due to small differences in the pupal and female morphology: presence of shagreen on the pupal abdominal pleura II and III, presence of 4 taeniate lateral setae on pupal abdominal segment $\mathrm{V}$ and shorter $(37 \mu \mathrm{m})$ cerci in the adult female. We regard these differences as exceeding what can be expected to be intraspecific variation in Zavrelia, but do not wish to formally describe this specimen as a separate species due to the limited number of specimens and lack of males for comparison with other Zavrelia species. Moreover, based on the pupal characters alone, the additional specimen from Tennessee is very similar to Zavrelia elenae. It is tempting to identify the $\mathrm{P} q$ from Tennessee as $Z$. elenae on this basis, but given the huge geographical distance between these two localities and the lack of crucial information on other life stages, we choose to leave the Tennessee specimen unnamed at this point.

\section{Zavrelia pentatoma Kieffer \& Bause in Bause, 1914}

Zavrelia pentatoma Kieffer \& Bause in Bause, 1913: 73, 76-78, 100; Brundin, 1948, 1949; Goetghebuer, 1937-1954 (morphology, keys, distribution).

Zavrelia atrofasciata Kieffer, 1921: 78, syn. n. Male adult type: Poland, Silesia, M. Harnisch (not located).

Zavrelia nigritula Goetghebuer, 1921: 131. Synonymy by Brundin, 1947.

Stempellina paludosa Goetghebuer, 1931: 114, syn. n.

\section{Diagnostic characters}

Zavrelia pentatoma can be separated from other Zavrelia species by the following combination of characters. Adult male with wing length c. $1.3 \mathrm{~mm}, 3.7$ times longer than broad; AR about 1.2; frontal tubercle minute; anal point with numerous $(>40)$ spinules between long anal crests; several (6-11) strong median tergite setae placed at some distance from anal point base; median volsella short, stout, with simple and subulate lamellae. Adult female with AR c. 0.28; vaginal floor absent, but lateral margin of vagina with slight ventral extension; spermathecal duct far longer than notum and rami combined, c. $300 \mu \mathrm{m}$ long; notum considerably longer than rami; diameter of seminal capsule large (c. $63 \mu \mathrm{m}$ long), much shorter than length of notum, but longer than cercus (c. $47 \mu \mathrm{m}$ ). Pupa with weakly developed cephalic tubercle; thoracic horn long and thin with numerous small chaetae scattered around middle; thorax smooth except for small area of granulation along scutal suture; anterior dorsocentrals longer than posterior dorsocentrals; microspinule patches on tergite II-V large, covering most of tergite; microspinule patches on tergite VI two broad longitudinal rows; pleura II-VI with shagreen; anal lobe with a fringe of 14-19 taeniate setae. Larva with well developed, (c. $30 \mu \mathrm{m}$ long), pointed spur on antennal pedestal; AR 1.2; antennal segment 1 c. 75-90 $\mu \mathrm{m}$ long; distal Lauterborn organ on $2 \mu \mathrm{m}$ long pedicel, basal Lauterborn organ without pedicel placed close to base of antennal segment 2; S3 simple.

\section{Description}

Adult male ( $\mathrm{n}=5$, unless otherwise stated). Length 1.7-1.9, $1.8 \mathrm{~mm}$; wing length 1.19-1.46, 1.35 (7) mm.

Colour: Body and head dark brown, some specimens with lighter brown ground colour with dark pedicel, eye, scutal stripes, postnotum and preepisternum, scutellum paler, haltere brown.

Head (Fig. 8A): Frontal tubercle minute, 2-3 $\mu \mathrm{m}$ long; Antenna (Fig. 8B) with AR 0.96-1.36, 1.21 (6); lengths of palpomeres (in $\mu \mathrm{m}$ ): 30; 30-42; 37; 114-166, 136; 


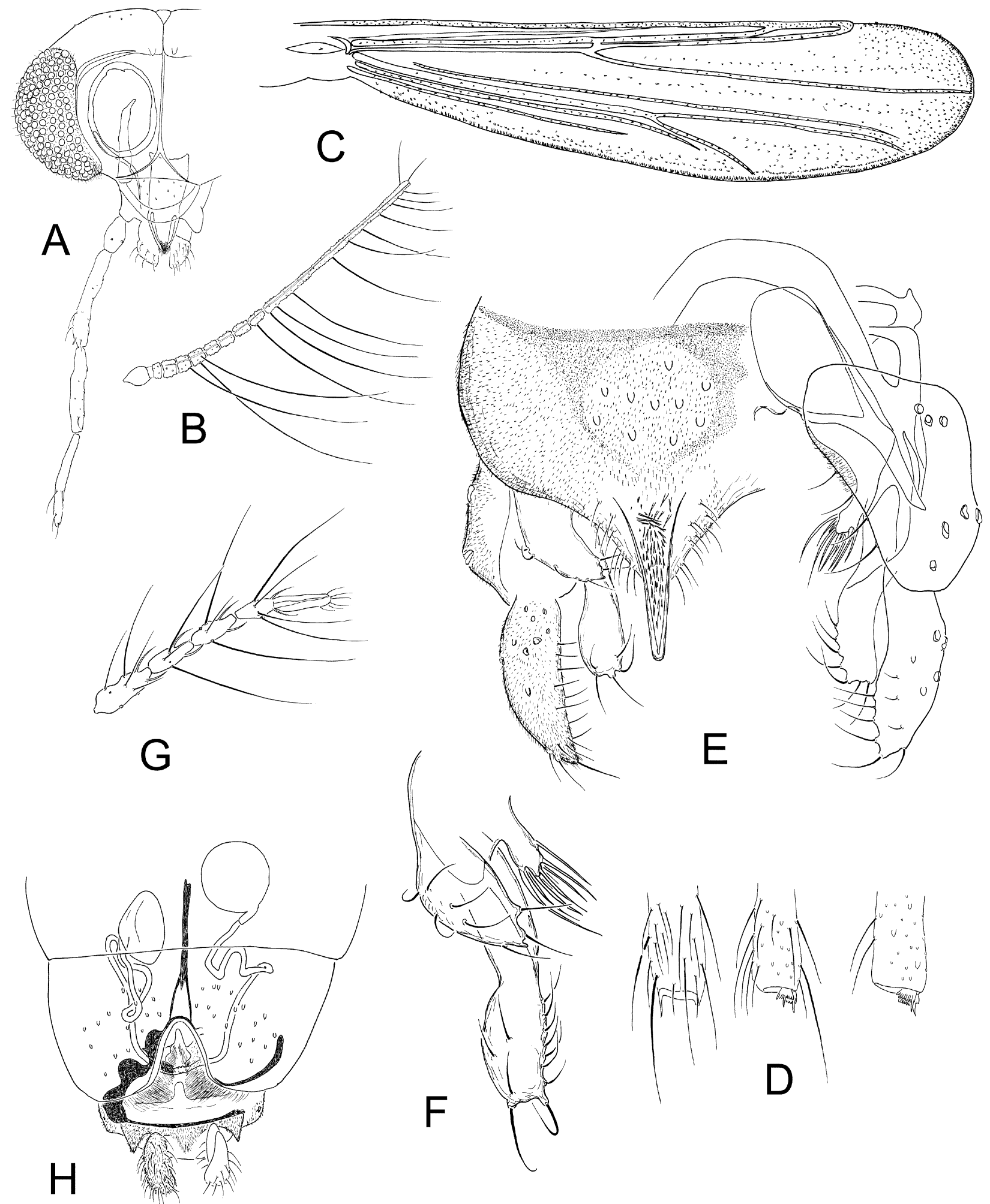

Fig. 8. Zavrelia pentatoma Kieffer \& Bause, imagines. (A-F) male: (A) head; (B) antenna; (C) wing; (D) apex of fore, mid and hind tibia; (E) hypopygium, dorsal and ventral view; (F) superior, median and inferior volsella. (G-H) female: (G) antenna; (H) genitalia.

90-120, 106; 95-141, 123 (4). Clypeus about $35 \mu \mathrm{m}$ long with 9-11 setae; tentorium c. $105 \mu \mathrm{m}$ long, $16 \mu \mathrm{m}$ wide; 2-3 inner verticals, 2-3 outer verticals, 2-3 post orbitals.

Thorax: Acrostichals 10-16, 14; dorsocentrals 7-10, 8; humerals 0 ; prealars 1 ; scutellars 6-9, 8; halterals 4-6, 5 .
Wing (Fig. 8C): cuneiform, 3.5-3.8, 3.7 times longer than broad; VR 1.29-1.40, 1.33; wing setation as in Fig. 8C. RM obvious to obscure.

Legs (Fig. 8D): Fore tibia with $19 \mu \mathrm{m}$ long spur; mid and hind tibiae with well separated, 10-14, $11 \mu \mathrm{m}$ and 
13-15 $\mu \mathrm{m}$ long combs, mid tibial combs with $23-24 \mu \mathrm{m}$ and 19-20 $\mu \mathrm{m}$ long spurs, hind tibial combs with 25-30, $27 \mu \mathrm{m}$ and 22-30, 26 long spurs. Lengths and ratios of leg segments in Table 1.

Hypopygium (Figs 8E-F): Anal tergite 102-114, 110 $\mu \mathrm{m}$ long with 6-11, 9 median tergite setae; laterosternite IX without setae; 20-26, 24 apical setae; anal point 45-63, $54 \mu \mathrm{m}$ long, basally $15 \mu \mathrm{m}$ broad with well developed crests, anal point distally thin $5 \mu \mathrm{m}$ wide; $36-50,43$ spinules between crests on anal point; small microtrichiafree areas present at base of anal point. Gonocoxite 84-105, $95 \mu \mathrm{m}$ long; gonostylus 63-81, $70 \mu \mathrm{m}$ long; HR $1.30-1.46,1.35$. Superior volsella digitiform with small apical point, medially directed, with 5 dorsal and 2 median setae on setiger, superior volsella sometimes with dorsolateral microtrichiae; median volsella stout, 15-21, $18 \mu \mathrm{m}$ long, medially directed, stem simple, bare, with rosette of simple and subulate, $15-25,19 \mu \mathrm{m}$ long lamellae; inferior volsella c. $58 \mu \mathrm{m}$ long, club-shaped, with several distal setae, dorsal surface without microtrichia.

Adult female $(\mathrm{n}=1)$. Length $1.6 \mathrm{~mm}$; wing length 1.28 $\mathrm{mm}$. Colour as for male, but paler.

Head: Antennae (Fig. 8G) with ultimate flagellomere $66 \mu \mathrm{m}$ long, AR 0.28; lengths of palpomeres (in $\mu \mathrm{m}$ ): 27 ; 27; 93; 81; 105. Clypeus with 10 setae.

Thorax: Acrostichals 13; dorsocentrals 7; humerals 2; prealars 1; scutellars 8; halterals 5 .

Wing: as male, except 3.0 times longer than broad. VR 1.28 .

Legs: As male.

Genitalia (Fig. 8H): Tergite IX $36 \mu \mathrm{m}$ long; sternite VIII with 34 setae; gonocoxite with 1 seta; sternite VIII forming narrow rim along ventral margin of vagina; gonocoxapodeme slightly curved; coxosternapodeme well developed with two obvious anterior and one posterior lobe. Notum including rami $132 \mu \mathrm{m}$ long, notum alone $105 \mu \mathrm{m}$ long. Seminal capsule diameter $63 \mu \mathrm{m}$ with $\mathrm{c}$. $300 \mu \mathrm{m}$ long spermathecal duct. Cercus $54 \mu \mathrm{m}$ long.

Pupa ( $\mathrm{n}=5$, unless otherwise stated). Length 2.3-2.4 $\mathrm{mm}$; abdomen 1.6-1.9, $1.8 \mathrm{~mm}$ long. Colour of pupal exuviae pale brownish with darker lateral margins on abdominal segment VIII.

Cephalothorax (Figs 9A-B): Cephalic tubercle weakly developed, $15 \mu \mathrm{m}$ long; frontal seta taeniate, 120-150, $141 \mu \mathrm{m}$ long; pedicel sheath tubercle absent. Thoracic horn 380-435, $397 \mu \mathrm{m}$ long, 21-24, $23 \mu \mathrm{m}$ wide with 3 $\mu \mathrm{m}$ long chaetae scattered around middle $1 / 3$; precorneals taeniate, arranged in triangular pattern, on obvious mound, 150-180, $165 \mu \mathrm{m}$ long, anterior setae placed closer together; median antepronotal taeniate, 2 lateral antepronotals: 1 taeniate, 1 sensillum basiconicum; 2 pairs dorsocentrals, anterior pair 75-90, $84 \mu \mathrm{m}$ and 54-75, $63 \mu \mathrm{m}$ long, posterior pair 45-60, $54 \mu \mathrm{m}$ long. Small area of granulation along median suture line dorsal to $\mathrm{Dc}_{1}$. Prealar tubercle well developed, broad, c. $55 \mu \mathrm{m}$ long.

Abdomen (Fig. 9C): TII almost covered with shagreen and microspinules, shagreen start well anterior to seta D1; hook row 105-144, $123 \mu \mathrm{m}$ wide with 51-58, 55 hooks.
TIII-V with large, square fields of microspinules, small posteromedian, oval area without armament; TVI with broad, longitudinal rows of microspinules and shagreen, almost forming a $\pi$-pattern; TVII-IX with anterolateral patches of shagreen. Segment II with 2D, 2V, 3 L setae; segment III with 3D, 2V, 3 L setae; segment IV with 3D, $2 \mathrm{~V}, 2$ simple and 1 semi-taeniate $\mathrm{L}$ setae; segment $\mathrm{V}$ with $3 \mathrm{D}, 3 \mathrm{~V}, 3$ taeniate L setae; segment VI-VII with $3 \mathrm{D}, 3 \mathrm{~V}$, 4 taeniate L setae; segment VIII with $1 \mathrm{D}, 1 \mathrm{~V}, 4$ taeniate L setae; segment IX with 1D seta on anal lobe, 14-19, 17 taeniate setae in anal fringe. 1 pair of O-setae present anteriorly on tergites II-VIII and anterolaterally on sternites II-VIII. Pleura II-VI with large fields of shagreen. Posterolateral spur on segment VIII occasionally bifurcate.

Larva ( $\mathrm{n}=5$, unless otherwise stated). Length c. 2.3 $\mathrm{mm}$, case c. $3 \mathrm{~mm}$ long. Head capsule brown, somewhat darker postoccipital rim and teeth on mandible and mentum. Live specimens not examined.

Head (Figs 9D-H): AR 1.09-1.27, 1.21; antennal pedestal 60-69, $65 \mu \mathrm{m}$ long with well developed, $30 \mu \mathrm{m}$ straight spur; antenna (Fig. 9D) with all segments well sclerotized, segment lengths (in $\mu \mathrm{m}$ ): 75-90, 85; 30-39, 34 ; 16-18, 17; 12-14, 12; 5-6; segment three inserted subapically on segment two; AAR 0.70-0.82, 0.77 . Antennal blade 105-120, 111 (4) $\mu \mathrm{m}$ long, pale, reaching well beyond tip of distal Lauterborn organ; peg of antennal segment two placed subapically on segment. Lauterborn organs $15 \mu \mathrm{m}$ long; proximal organ placed close to base of segment two without pedicel, apical organ on $2 \mu \mathrm{m}$ long pedicel; S3 and chaetulae simple; labral lamella with 32-40 (2) teeth. Mentum (Fig. 9E) with all lateral teeth similar in size and set an equal distance apart; ventromental plates medially barely reaching third lateral tooth of mentum, MVR 1.00-1.18, 1.11; premandible in Fig. 9F; mandible (Fig. 9G) with pecten mandibularis slightly convex, seta subdentalis $36-45,41 \mu \mathrm{m}$ long; postoccipital plate (Fig. 9H) broad.

Body: Hind parapod with 16 simple hooks; L2 apparently simple; anal tubules $30 \mu \mathrm{m}$ long; supraanal seta strong, 200-240, 222 (3) $\mu \mathrm{m}$ long; procercus c. $30 \mu \mathrm{m}$ long with 2 short (c. $120 \mu \mathrm{m}$ long) and 4 long (c. $640 \mu \mathrm{m}$ long) anal setae.

Material. Type material: Lectotype of Zavrelia pentatoma here designated: 1 pharate $\delta$ (ZSM) Bohemia and/or Moravia, J. Zavřel [examined]. Paralectotypes: At least $1 \delta^{*}, 19$ and $8 \mathrm{~L}$ Germany, Rhineland, Ludwigshafen, Neuhofen/Maudach, peat pits, v.1904, R. Lauterborn [imagines not located, larvae (ZSM) examined]; 2 P, Bohemia and/or Moravia, J. Zavřel [1 P (ZSM) examined].

Lectotype of Zavrelia nigritula here designated: 10 (IRSNB) Belgium, Flanders, Heusden, 5.v.1915, M. Goetghebuer; 4 paralectotype $\widehat{o}$ (IRSNB), 1 as lectotype, 3 Flanders, Destelbergen, 5.v.1915, M. Goetghebuer [all examined]; female paralectotype(s) not located.

Lectotype of Stempellina paludosa here designated: 10 (IRSNB) Belgium, Flanders, Heusden, 12.vi.1930, M. Goetghebuer [examined]; female paralectotype not located.

Additional material examined: Austria (ZSM): 7 o, 4 pex, 6 L, Lunz, Mittersee, Rotmoos, 9.vi.1942, A. Thienemann. China (ZSM): $1 \delta$ Jilin Province, road between Antu and Song- 


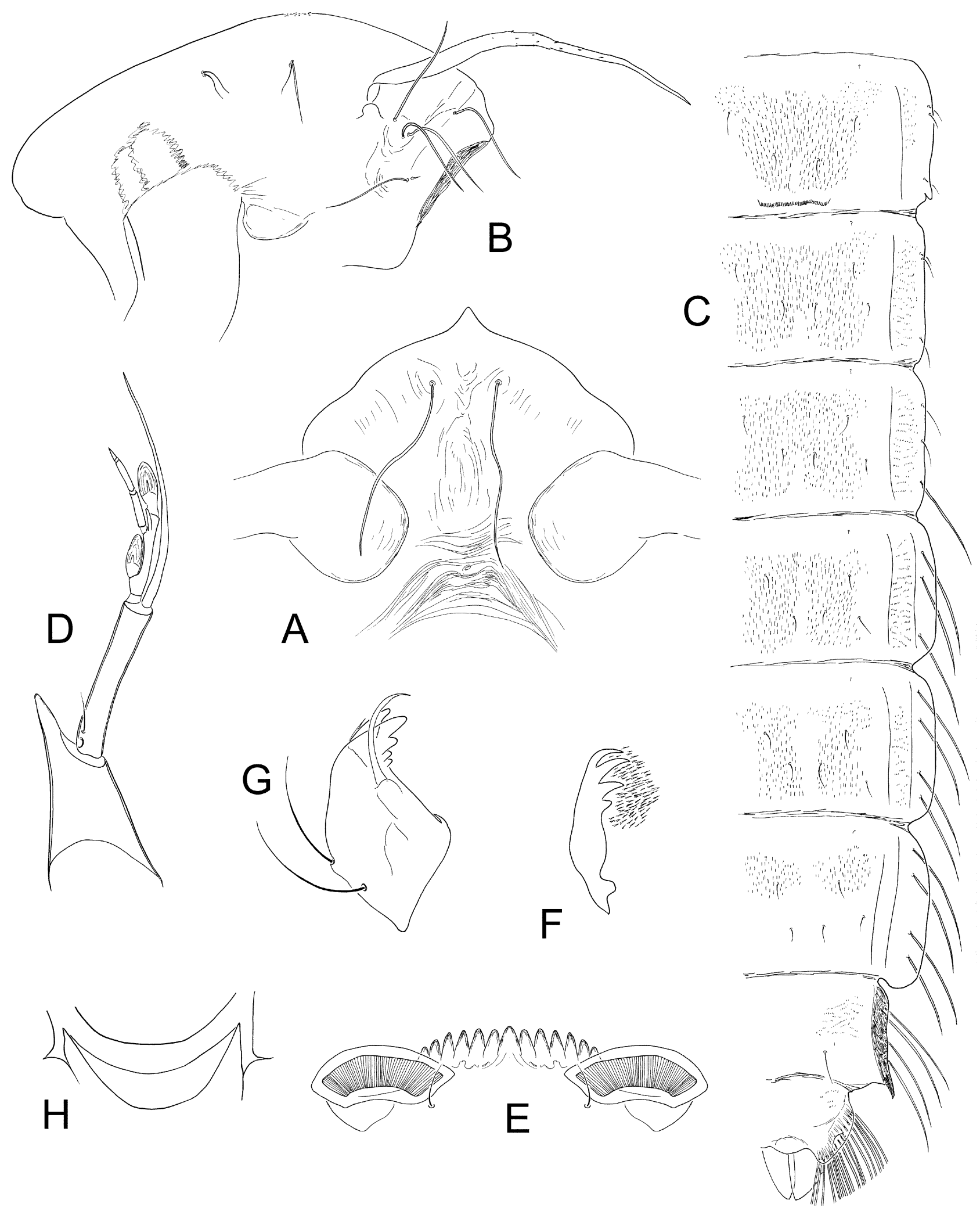

Fig. 9. Zavrelia pentatoma Kieffer \& Bause, immatures. (A-C) pupa: (A) frontal apotome; (B) thorax; (C) abdomen dorsal view. (D-H) larval head: (D) antenna; (E) mentum; (F) premandible; (G) mandible; (H) postoccipital plate.

jiang, 500-1000 m a.s.1., 12.vi.1980, E.J. Fittkau. Czech Republic (ZSM): $2 \mathrm{~L}$ and 2 larval cases, Bohemia and/or Moravia, J. Zavřel. Finland: 10 , 1 ㅇ (MZH) Punkasalmi, Akonniemi, Kortteenoja, 17.vi.1973, B. Lindeberg; 1 đ (MZH) Punkasalmi, Kauvonniemi, Ullinsuo, forest ditch, 19.vi.1972, B.
Lindeberg; 1 đิ (MZH) Hyvinkää, Keravanjoki, 7.vi.1983, J. Tuiskunen; 20 (MZH) Vehkalahti, Paijärvi, Suuri Karjalaistensuo, 30.v.1983, J. Tuiskunen. Germany (ZSM): $20^{\wedge} 3$ pex, 3 L

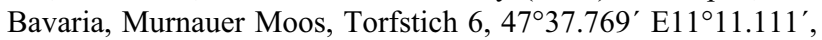
11.vii.1979, 18.vii.1979, F. Reiss; $1 \delta^{t}$ as previous except Rollis- 


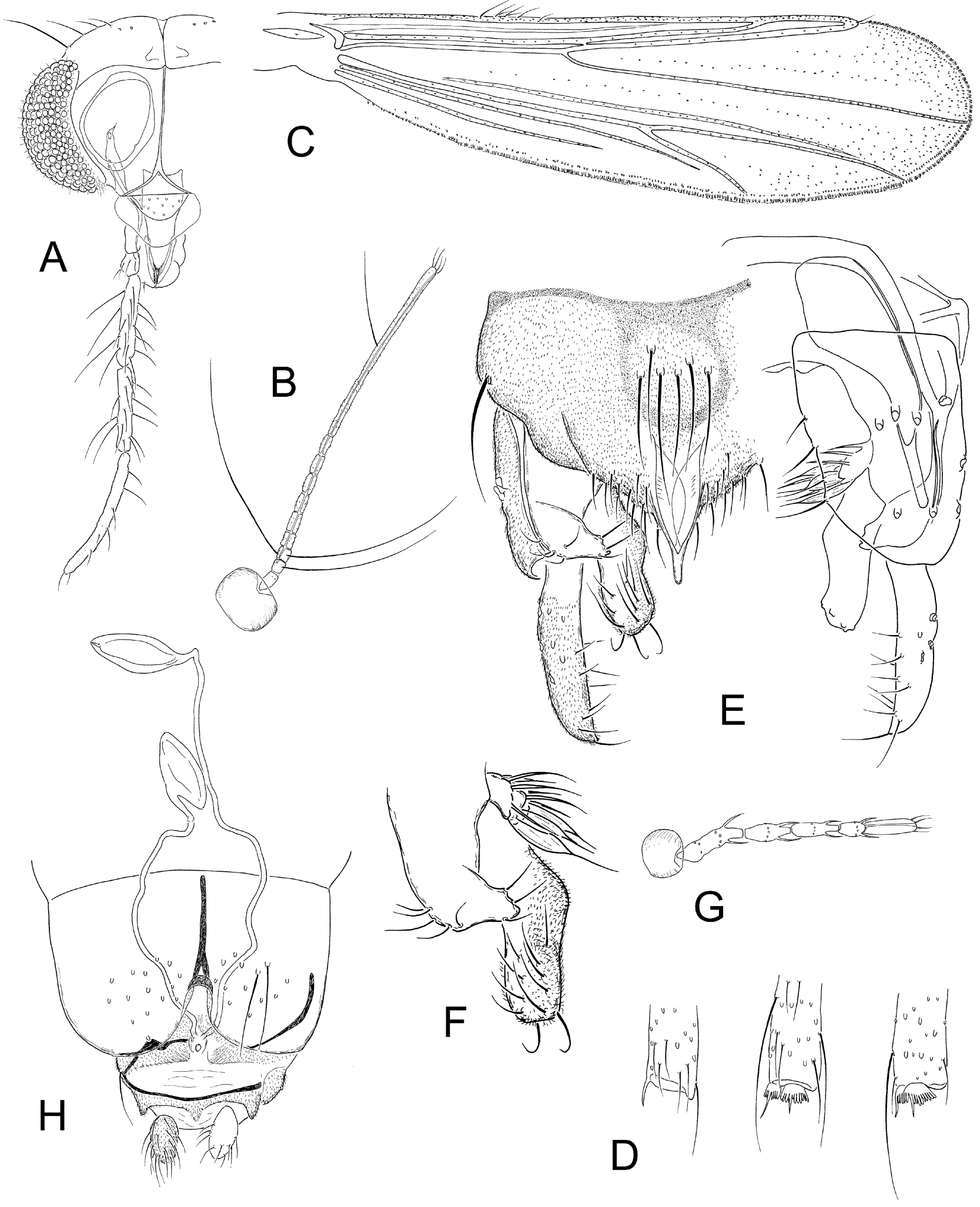

Fig. 10. Zavrelia sinica sp. n., imagines. (A-F) male: (A) head; (B) antenna; (C) wing; (D) apex of fore, mid and hind tibia; (E) hypopygium, dorsal and ventral view; $(F)$ superior, median and inferior volsella. $(\mathrm{G}-\mathrm{H})$ female: $(\mathrm{G})$ antenna; $(\mathrm{H})$ genitalia.

chsee, $47^{\circ} 39.778^{\prime} \mathrm{N}, 11^{\circ} 09.993^{\prime} \mathrm{E}, 15 . x .1979 ; 3 \sigma^{\wedge}$ Bavaria, Allgäu, Immenstadt, Teufelsee, 29.vi.-2.vii.1965, F. Reiss; 30 Bavaria, Fürstenfeldbruck, Schluifelder Moos, 23.v.1989, W. Schacht; 1 to Baden-Württemberg, Bodensee, Wahlwies, 12.v.1966, F. Reiss; 10 Hessen, Fulda, Wasserkuppe, 10.iv.-29.v.1967, J. Lehmann; 1 to Thüringen, Nationalpark Hainich, Silbersee, $51^{\circ} 00.051^{\prime} \mathrm{N}, 10^{\circ} 25.402^{\prime} \mathrm{E}, 18 . \mathrm{vi} .2005, \mathrm{M}$. Kotrba. Sweden (ZSM): 1 pex Lappland, Abisko, Kånavaggi, small pit near lake, $695 \mathrm{~m}$ a.s.1., 20.vi.1936, A. Thienemann. 
Turkey (ZSM): 1 ơ Prov. Hakkari, S Yüksekova, 1700 m a.s.l., 28.vi.1985, W. Schacht.

Remarks. The male and female types of Zavrelia pentatoma could not be located. The pupal type material is from a different locality than the larval sample from which adults were reared (Bause, 1913), but are nevertheless part of the type material since both Bause and Kieffer (in Bause, 1913) are credited the authorship of this species (Spies, 2005). The larvae from Bohemia/Moravia in the Thienemann collection (ZSM), collected by Zavřel, are not regarded as part of the type material since the larval description in Bause (1913) explicitly is based on the Lauterborn material. The pharate male examined (leg. Zavřel) is designated lectotype for future stability of the species taxonomy.

The type material of Zavrelia atrofasciata was not located, and is probably lost (W. Giłka, pers. comm.). The original description (Kieffer, 1921) is quite detailed however, and is conspecific with the morphology of Z. pentatoma except for a slightly different shape and fewer setae on the superior volsella (club-shaped and 3-4 setae respectively). The larger, more developed cross vein RM reported for Z atrofasciata by Kieffer (1921) and Goetghebuer (1937-1954) is an intraspecifically variable character in Z. pentatoma, and is different even in specimens from the same locality and date. Thus, we regard Kieffer's (1921) observations to be minor misinterpretations and list $Z$. atrofasciata, as suspected by Giłka (2002), as a junior synonym of $Z$. pentatoma.

Goetghebuer (1921) considered Zavrelia nigritula to be a darker variation of $Z$. pentatoma, and even suggested that the differences in colouration could be associated with the preservation of the Lauterborn specimens Kieffer used. The male syntypes present in IRSNB were examined and are judged to be conspecific with $Z$. pentatoma. Intraspecific variation in body pigmentation is found in other chironomid species (e.g. Kobayashi \& Hayashi, 2001; Matěna, 1995) and is clearly also the case for $Z$. pentatoma. Goetghebuer (1937-1954) reports Z. nigritula to have palpomeres of increasing length, but this is not the case for the type material examined where all specimens have palpomere three longer than palpomere four. Thus, we agree with Brundin (1947) and confirm the synonymy with $Z$. pentatoma.

Goetghebuer (1931) included both male and female symbols in the original description of $S$. paludosa, but perhaps apart from the colouration and the wing, the description is based only on the male (e.g., no female antenna described). The male type in IRSNB is here designated lectotype to stabilize the taxonomy. Examination of this specimen revealed that Stempellina paludosa is conspecific with $Z$. pentatoma.

Zavrelia pentatoma is found in or near peat pits, moor ponds and moor lakes rich in humic acids and with relatively low pH (Brundin, 1949) (c. pH 5.5 in Rollischsee, own observation). The larvae build transportable cases of detritus, sand and diatoms (Lauterborn, 1905, Figs 8, 9), and seem to be adapted to a life in temporary, oxygenpoor, shallow waters (Brundin, 1949). Although adult specimens have been collected in Bavaria in November, the emergence period is mainly midsummer (op. cit.; this study). The species is widespread in Europe and is also recorded from the eastern Palaearctic region (Sæther \& Spies, 2004; this study).

\section{Zavrelia sinica sp. $\mathbf{n}$.}

\section{Diagnostic characters}

Zavrelia sinica can be separated from other Zavrelia species by the following combination of characters. Length of adult male c. $2 \mathrm{~mm}$; AR about 1.1; frontal tubercle large, tubular; anal point without spinules between long, high crests; c. 6 strong median tergite setae placed at some distance from anal point base; anal point crests not reaching apex of anal point; superior volsella with obvious constriction in apical $1 / 3$ of setiger. Adult female with AR c. 0.29; vaginal floor absent, but lateral margin of vagina with slight ventral extension; spermathecal duct far longer than notum and rami combined, c. $360 \mu \mathrm{m}$ long; notum considerable longer than rami; diameter of seminal capsule c. $66 \mu \mathrm{m}$, much shorter than length of notum; cercus short, $36 \mu \mathrm{m}$ long. Pupa with well developed cephalic tubercle; thoracic horn long and thin, with numerous small chaetae scattered on distal 2/3; thorax with small areas of granulation dorsoanteriorly in particular along scutal suture and posterior to thoracic horn; anterior dorsocentrals slightly longer than posterior dorsocentrals; microspinule patches on tergite II-V large, covering most of tergite; microspinule patches on tergite VI two broad semi-triangular patches; pleura II-VI with shagreen; segment $\mathrm{V}$ with 3 lateral taeniate setae; anal lobe with 18 taeniate setae in fringe. Larva with well developed (c. $21 \mu \mathrm{m}$ long), digitiform spur on long (c. 84 $\mu \mathrm{m}$ ) antennal pedestal; antennal segment 1 c. $66 \mu \mathrm{m}$ long; AR 0.90; distal Lauterborn organ on $14 \mu \mathrm{m}$ long pedicel, basal Lauterborn organ on $6 \mu \mathrm{m}$ pedicel positioned $1 / 3$ along length of antennal segment 2; antennal blade c. 100 $\mu \mathrm{m}$ long; $\mathrm{S} 3$ simple.

\section{Description}

Adult male ( $\mathrm{n}=3$, unless otherwise stated). Length 1.4-2.5, $1.8 \mathrm{~mm}$; wing length 1.08-1.09 (2).

Colour: Body and head ground colour brown, dark pedicel, scutal stripes, postnotum and median anepisternum. Scutellum paler, haltere brown, eye blackish.

Head (Fig. 10A): Frontal tubercle well developed, 12-18, $15 \mu \mathrm{m}$ long; antenna (Fig. 10B) with AR 1.03-1.11, 1.08; lengths of palpomeres (in $\mu \mathrm{m}$ ): 20-25, $22 ; 30 ; 105 ; 95-101,99 ; 150$. Clypeus about $50 \mu \mathrm{m}$ long with 10 setae; tentorium c. $80 \mu \mathrm{m}$ long, $15 \mu \mathrm{m}$ wide; 3 inner verticals, 3 outer verticals, 1 postorbital.

Thorax: Acrostichals 9-11, 10; dorsocentrals 6-7; humerals 0 ; prealars 1; scutellars 4-6, 5; halterals 5 .

Wing (Fig. 10C): Cuneiform, 3.2 times longer than broad $(\mathrm{n}=2)$; VR 1.27-1.40 (2); wing setation as in Fig. $10 \mathrm{C}$.

Legs (Fig. 10D): Fore tibia with 15-18 $\mu \mathrm{m}$ long spur; mid and hind tibiae with well separated, 10-12 $\mu \mathrm{m}$ and 12-15 $\mu \mathrm{m}$ long combs, mid tibial combs with $20 \mu \mathrm{m}$ long 


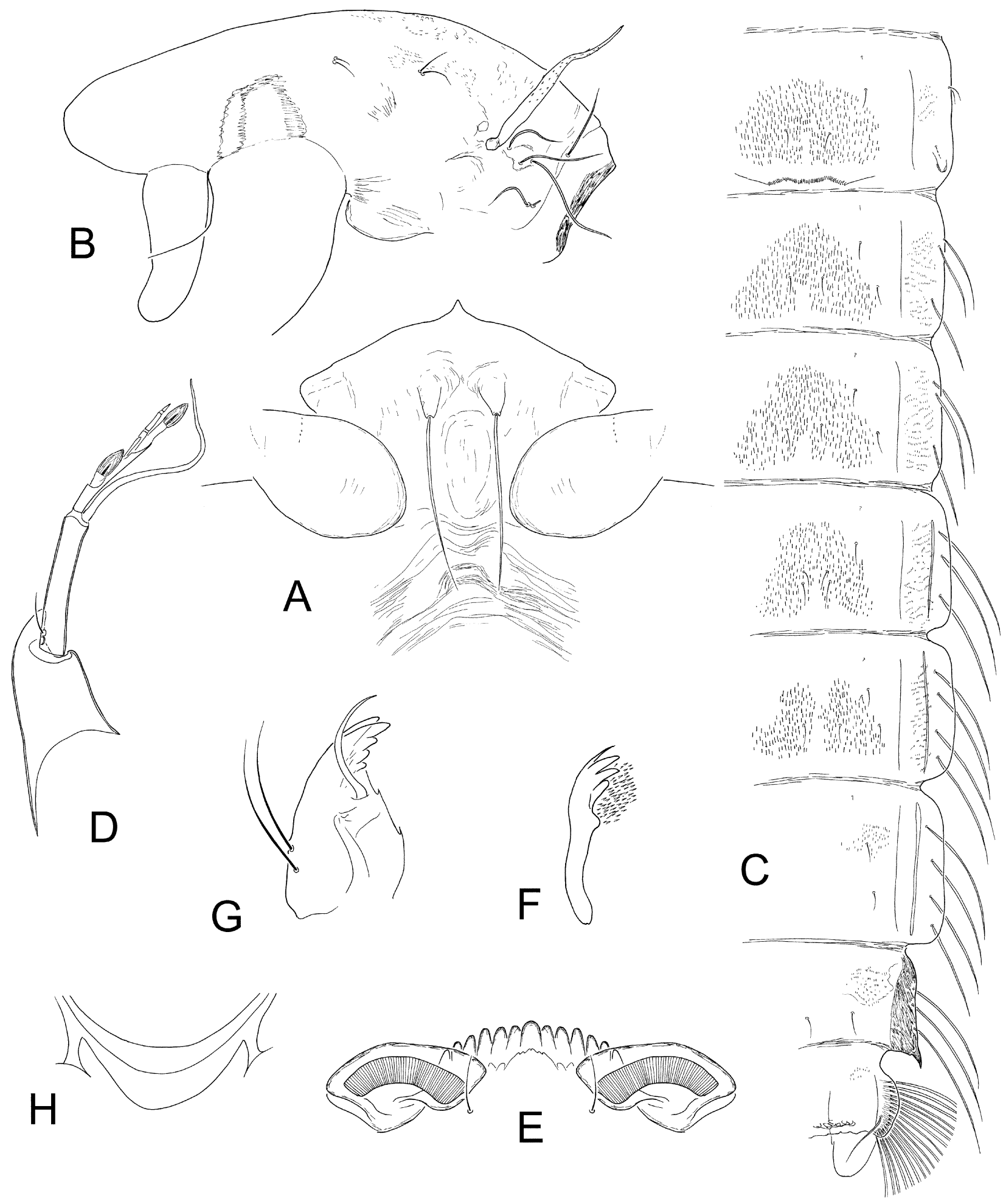

Fig. 11. Zavrelia sinica sp. n., immatures. (A-C) pupa: (A) frontal apotome; (B) thorax; (C) abdomen dorsal view. (D-H) larval head: (D) antenna; (E) mentum; (F) premandible; $(\mathrm{G})$ mandible; $(\mathrm{H})$ postoccipital plate.

spurs, hind tibial combs with 25 and $20 \mu \mathrm{m}$ long spurs. Lengths and ratios of leg segments in Table 1.

Hypopygium (Figs 10E-F): Anal tergite 93-105, 98 $\mu \mathrm{m}$ long with 6-8 median tergite; laterosternite IX with seta; 24-32, 27 apical setae; anal point 40-51, $45 \mu \mathrm{m}$ long, basally $12-16,14 \mu \mathrm{m}$ broad with well developed, high crests, anal point distally thin $2-3 \mu \mathrm{m}$ wide; spinules absent from anal point; small microtrichia-free areas present at base of anal point. Gonocoxite 75-99, $84 \mu \mathrm{m}$ long; gonostylus 50-69, $57 \mu \mathrm{m}$ long; HR 1.43-1.50, 1.48. Superior volsella digitiform with small apical point, medially directed, with 4-6, 5 dorsal and 2 median setae on setiger, otherwise bare; median volsella stout, 15-18, 17 $\mu \mathrm{m}$ long, medially directed, stem bare, with rosette of 
simple and subulate, 15-27, $21 \mu \mathrm{m}$ long lamellae; inferior volsella c. $45 \mu \mathrm{m}$ long, angled median margin, with several distal setae, dorsal surface with microtrichia medially.

Adult female $(\mathrm{n}=1)$. Length $2.4 \mathrm{~mm}$; wing unfolded. Colour as male, but somewhat paler (could be due to storage in alcohol).

Head: Antenna (Fig. 10G) with ultimate flagellomere $66 \mu \mathrm{m}$ long, AR 0.29; frontal tubercles pale dots; lengths of palpomeres (in $\mu \mathrm{m}): 21 ; 30 ; 90 ; 75 ; 126$. Clypeus with 10 setae.

Thorax: Acrostichals 13; dorsocentrals 7; humerals 5; prealars 1; scutellars 4; halterals 5 .

Wing: As male.

Legs: As male.

Genitalia (Fig. 10H): Tergite IX $51 \mu \mathrm{m}$ long; sternite VIII with 28 setae; gonocoxite with 1 seta; sternite VIII forming narrow rim along ventral margin of vagina; gonocoxapodeme slightly curved; coxosternapodeme comparatively weakly developed with obvious anterior lobe. Notum including rami $93 \mu \mathrm{m}$ long, notum alone 63 $\mu \mathrm{m}$ long. Seminal capsule diameter $66 \mu \mathrm{m}$ with c. $360 \mu \mathrm{m}$ long spermathecal duct. Cercus $36 \mu \mathrm{m}$ long.

Pupa ( $\mathrm{n}=5$, unless otherwise stated). Length 2.4-2.8, $2.6 \mathrm{~mm}$; abdomen 1.7-2.0, $1.9 \mathrm{~mm}$ long. Colour of pupal exuviae pale brownish with darker lateral margins on abdominal segment VII-IX.

Cephalothorax (Figs 11A-B): Cephalic tubercle well developed, 40-45, $43 \mu \mathrm{m}$ long; frontal seta taeniate, 145-150, $149 \mu \mathrm{m}$ long; pedicel sheath tubercle absent. Thoracic horn 270-300, $288 \mu \mathrm{m}$ long, 20-30, $24 \mu \mathrm{m}$ wide with 4-7 $\mu \mathrm{m}$ long chaetae scattered on distal $2 / 3$; precorneals taeniate, arranged in triangular pattern, on obvious mound, 100-180, $120 \mu \mathrm{m}$ long (anterior seta slightly longer), anterior two setae placed closer together; median antepronotal taeniate c. $100 \mu \mathrm{m}$ long, 2 lateral antepronotals: 1 taeniate c. $85 \mu \mathrm{m}$ long, 1 long sensillum basiconicum; 2 pairs dorsocentrals, anterior pair 30-48, $35 \mu \mathrm{m}$, posterior pair $30 \mu \mathrm{m}$ long. Small area of granulation along median suture line dorsal to $\mathrm{Dc}_{1}$. Prealar tubercle moderately developed, wide, c. 30-40 $\mu \mathrm{m}$ long.

Abdomen (Fig. 11C): TII with a large, rectangular microspinule patch, microspinules start anterior to seta D1, small microspinule-free line medioposteriorly; hook row 114-135, $123 \mu \mathrm{m}$ wide with 42-52, 47 hooks. TIII-V with large, semi-square fields of microspinules (anterior patch margin convex), small posteromedian, oval area without armament; TVI with broad, longitudinal patches of microspinules and shagreen, patches wider posteriorly; TVII-IX with anterolateral patches of shagreen. Segment II with 2D, 1-2V, 3 L setae; segment III with $3 \mathrm{D}, 1-2 \mathrm{~V}, 3$ taeniate L setae; segment IV with 3D, $2-3 \mathrm{~V}, 3$ taeniate $\mathrm{L}$ setae; segment $\mathrm{V}$ with $3 \mathrm{D}, 3 \mathrm{~V}, 3$ taeniate L setae; segment VI-VII with $2-3 \mathrm{D}, 3 \mathrm{~V}, 4$ taeniate L setae; segment VIII with $1 \mathrm{D}, 1 \mathrm{~V}, 3$ taeniate $\mathrm{L}$ setae; segment IX with 1D seta on anal lobe, 17-20, 18 taeniate setae in anal fringe. 1 pair of O-setae present anteriorly on tergites II-VIII and anterolaterally on sternites II-VIII. Pleura II-VI with large fields of shagreen.
Posterolateral spur on segment VIII occasionally bifurcate.

Larva ( $\mathrm{n}=1$, tentatively associated). Length c. $2.3 \mathrm{~mm}$, case c. $3 \mathrm{~mm}$ long. Head capsule brown, somewhat darker postoccipital rim, teeth on mandible and mentum. Live specimens not examined.

Head (Figs 11D-H): Length c. $225 \mu \mathrm{m}$, width c. 150 $\mu \mathrm{m}$; AR 0.90; antennal pedestal $84 \mu \mathrm{m}$ long with well developed, $21 \mu \mathrm{m}$ digitiform spur; antenna (Fig. 11D) with all segments well sclerotized, segment lengths (in $\mu \mathrm{m}): 66 ; 45 ; 12 ; 10 ; 6$; segment three inserted subapically on segment two; AAR 1.27. Antennal blade $99 \mu \mathrm{m}$ long, pale, reaching well beyond tip of distal Lauterborn organ; peg of antennal segment two placed subapically on segment. Lauterborn organs $15 \mu \mathrm{m}$ long; proximal organ positioned 1/3 along length of segment two on $6 \mu \mathrm{m}$ long pedicel, apical organ on $14 \mu \mathrm{m}$ long pedicel; S3 and chaetulae simple; labral lamella with 26 teeth. Mentum (Fig. $11 \mathrm{E})$ with all lateral teeth similar in size, set an equal distance apart; ventromental plates medially reaching middle of third lateral tooth of mentum, MVR 1.13; premandible in Fig. 11F; mandible (Fig. 11G) with pecten mandibularis slightly convex, seta subdentalis $42 \mu \mathrm{m}$ long; postoccipital plate (Fig. 11H) broad.

Body: Hind parapod with 16 simple hooks; L2 apparently simple; two pairs of anal tubules 45 and $66 \mu \mathrm{m}$ long; supraanal seta strong, $230 \mu \mathrm{m}$ long; procercus c. 30 $\mu \mathrm{m}$ long with 2 short (c. $150 \mu \mathrm{m}$ long) and 4 long (c. 390 $\mu \mathrm{m}$ long) anal setae.

Material. Holotype Pô (ZSM) China. Jilin Province, stream $10 \mathrm{~km} \mathrm{~S}$ of Songiiang, drift, 12.vi.1980, E.J. Fittkau. 8 paratypes: $1 \mathrm{P}+4 \mathrm{Pex}, 1 \mathrm{~L}$ as holotype; 20 (WG) North Korea, Kymgang-san, netting, 26.vi.-02.vii.1981, W. Krzemiński.

Etymology. "sinica", Latin adjective meaning Chinese, referring to the country in which the holotype was found.

Remarks. The adult male of Zavrelia sinica is perhaps most similar to Z. elenae Zorina, 2008 and Z. pseudopentatoma Zorina, 2008, but can be separated from both these species by having anal point crests that do not reach the anal point apex and by the presence of distinct microtrichia-free areas around the base of the anal point. The pupa of $Z$. sinica closely resembles that of $Z$. pseudopentatoma, but can be separated by having semitaeniate lateral setae on the abdominal segment III and shagreen on pleura II-VI. The larva is almost identical to that of $Z$. elenae and can only be separated by antennal morphometrics and the number of spines on mola.

Zavrelia sinica was found in a stream along the road between Antu and Songjiang in the Jilin Province (c. 10 $\mathrm{km} \mathrm{S}$ of Songjiang), and in the North Korean Kymgang-san mountains. The larvae build transportable cases of comparatively coarse sand grains.

\section{Zavrelia tusimatijea (Sasa \& Suzuki, 1999)}

Tanytarsus tusimatijeus Sasa \& Suzuki, 1999: 30.

Zavrelia tusimatijeus [sic!]: Ekrem, 2002: 33, new combination.

\section{Diagnostic characters}

Zavrelia tusimatijea can be separated from other Zavrelia species by the following combination of charac- 


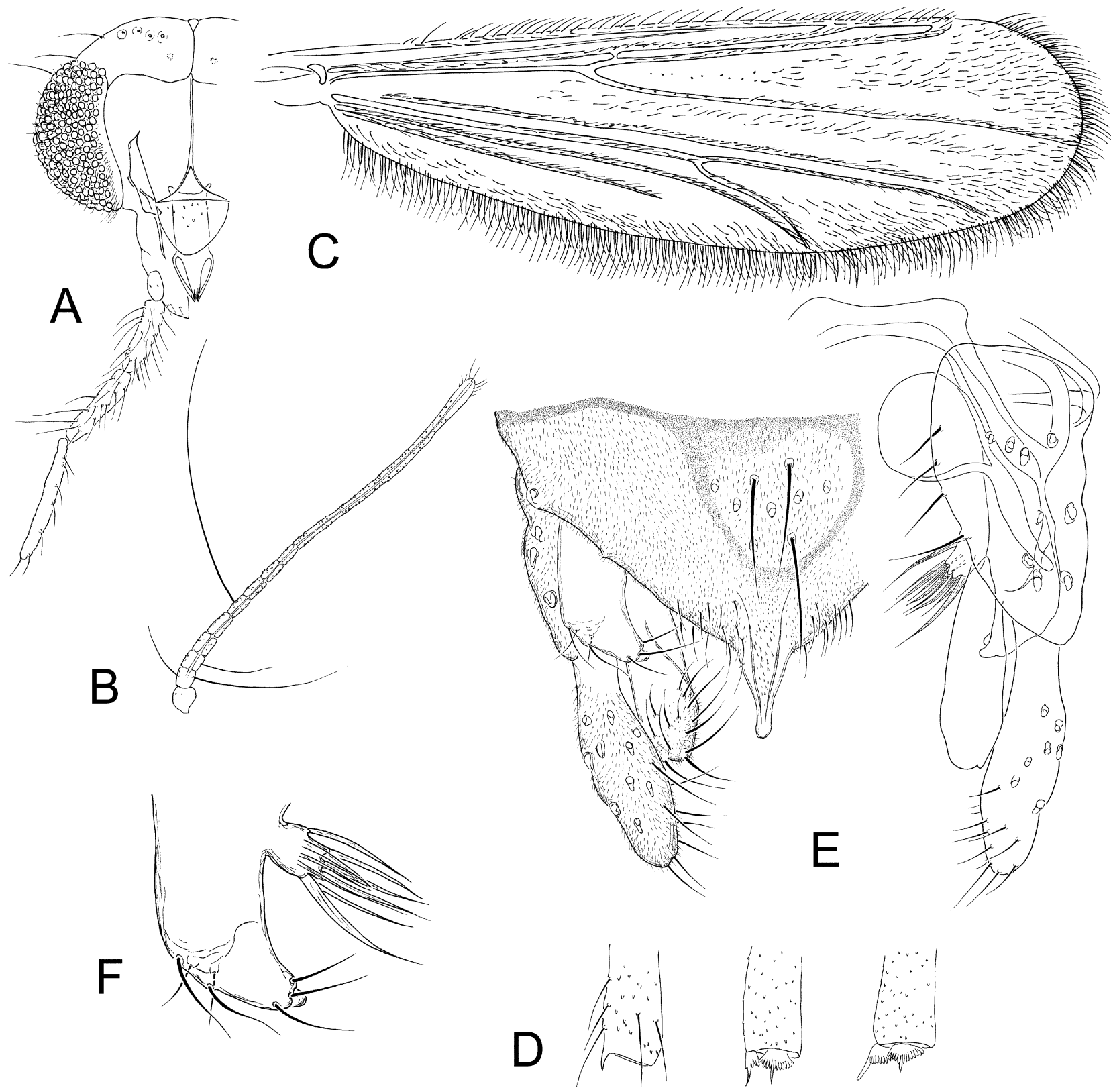

Fig. 12. Zavrelia tusimatijea (Sasa \& Suzuki), male imago. (A) head; (B) antenna; (C) wing; (D) apex of fore, mid and hind tibia; (E) hypopygium, dorsal and ventral view; (F) superior and median volsella.

ters: Frontal tubercle small white spot, AR c. 1.2; anal point with numerous small spinules between well developed crests; apex of superior volsella divided into a ventral point and a dorsal lobe, two setae placed on ventrolateral sculpturing of setiger.

\section{Description}

Adult male $(\mathrm{n}=1)$. Length $2.4 \mathrm{~mm}$; wing length 1.50 $\mathrm{mm}$.

Colour: Body more or less uniformly dark brown with light brown legs and scutellum. Eyes somewhat darker ventrally.

Head (Fig. 12A): Frontal tubercle only small whitish dot; antenna (Fig. 12B) with 13 flagellomeres of which only 10 are easily discernible; AR (on 10 flagellomeres) 1.23 ; lengths of palpomeres (in $\mu \mathrm{m}): 35 ; 35 ; 100 ; 110$;
165. Clypeus about $50 \mu \mathrm{m}$ long with 11 setae; tentorium c. $100 \mu \mathrm{m}$ long, $20 \mu \mathrm{m}$ wide; 3 inner verticals, 3 outer verticals, 2 postorbital.

Thorax: Acrostichals 16; dorsocentrals 9; humerals 0; prealars 1; scutellars 6; halterals 7 .

Wing (Fig. 12C): Cuneiform, extensively covered with macrotrichiae in cells and on most veins, sub costa and media bare, brachiolum with 1 seta, squama bare.

Legs (Fig. 12D): Front tibia with small scale, $20 \mu \mathrm{m}$ long spur; middle tibial combs $15 \mu \mathrm{m}$ long with $30 \mu \mathrm{m}$ and $20 \mu \mathrm{m}$ long spurs; hind tibial combs $15 \mu \mathrm{m}$ long with $30 \mu \mathrm{m}$ and $25 \mu \mathrm{m}$ long spurs. Lengths and ratios of leg segments in Table 1.

Hypopygium (Figs 12E-F): Anal tergite $107 \mu \mathrm{m}$ long with 9 strong median tergite setae, laterosternite IX with seta; c. 30 apical setae. Anal point well developed with c. 
20 small spinules scattered between long, low anal crests, apex rounded; no microtrichia free area around base of anal point. Superior volsella triangular with 3 dorsal, 2 ventral and 2 median setae on setiger; setiger with apex horizontally divided in ventral point and dorsal lobe, rounded knob with 2 setae ventrolaterally; microtrichia apparently absent from superior volsella. Median volsella short knob, with medially directed subulate lamellae. Inferior volsella slightly club-shaped with about 12 dorsoapical setae. Inner margin of gonocoxite with 4 strong setae.

Material. Holotype ơ (NSMT), Japan, Tsushima Island, Izumi, Kamitsushima, 26.iii.1998, H. Suzuki [examined].

Remarks. This species was originally described as a member of Tanytarsus, but both the original description and examination of the holotype reveal that it belongs to Zavrelia. This was recognized by Ekrem (2002). Zavrelia tusimatijea has so far only been recorded from its type locality on Tsushima Island in the Korea Strait and this record constitutes the southernmost distribution of Zavrelia in the Palaearctic region.

\section{IDENTIFICATION KEYS}

\section{Key to adult males of Zavrelia}

1 Anal point densely covered with strong spines (Fig. 8E)....

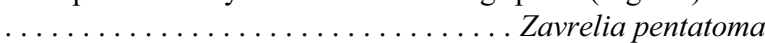

- Anal point bare, with microtrichia, short spinules or two spines only (Figs 1E, 10E) . . . . . . . . . . . 2

2 Anal point with two spines and few microtrichia between anal point crests (Guo \& Wang, 2007, Fig. 3)........... ........................ Zavrelia bragremia

- Anal point bare or with microtrichia or small spinules only

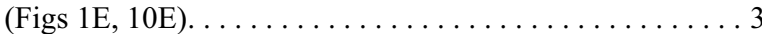

3 Setiger of superior volsella with obvious constriction in apical $1 / 3$; anal point bare or with microtrichia in between crests (Figs $5 \mathrm{E}, 10 \mathrm{~F}) \ldots \ldots \ldots \ldots \ldots \ldots \ldots \ldots \ldots$

- Setiger of superior volsella without obvious constriction in apical $1 / 3$; anal point with numerous microtrichia or small spinules (Figs 1F, 12E, F) . . . . . . . . . . . 6

4 Setiger of superior volsella with pointed apex (Fig. 5E) .... ........................ Zavrelia clinovolsella

- Setiger of superior volsella with somewhat rectangular apex

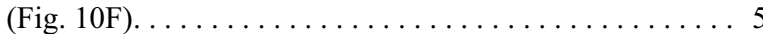

5 Anal point with only few microtrichia in between crests; distinct microtrichia-free areas on anal tergite around base of anal point (Fig. 10E). . . . . . . . . . . Zavrelia sinica

- Anal point with numerous microtrichia in between crests; microtrichia present all around base of anal point (Zorina, 2008, Figs 13-14). . . . . . . . Zavrelia pseudopentatoma

6 Setiger of superior volsella with additional apical lobe and ventrolaterally sculpturing bearing two setae (Fig. 12F). ....

Zavrelia tusimatijea

- Setiger of superior volsella without additional lobe and

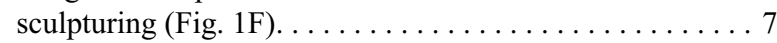

7 AR about 0.6; anal point short, with low crests (Fig. 3F).... .......................... Zavrelia casasi

- AR about 0.7 or higher; anal point long, with high crests (Fig. 6F) . . . . . . . . . . . . . . . . . . . 8

8 Anal point without microtrichia in between crests (Zorina, 2008, Figs 1-2).................. Zavrelia elenae

- Anal point with microtrichia in between crests (Fig. 1E). . 9

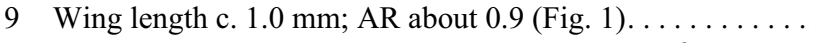

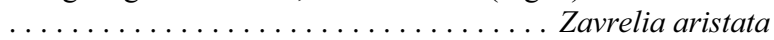
Wing length c. $1.4 \mathrm{~mm}$; AR about 0.75 (Fig. 6). ......... ........................ Zavrelia hudsoni

\section{Key to adult females of Zavrelia}

The females for the following species are unknown or undescribed: Zavrelia bragremia, Z. casasi, Z. clinovolsella, Z. elenae, Z. pseudopentatoma and Z. tusimatijea. Thus, caution must be taken when using the key below.

1 Spermathecal ducts 3 times longer than length of notum and rami combined; coxosternapodeme with small anterior and posterior lobes (Fig. 10H) . . . . . . . . . Zavrelia sinica

- Spermathecal ducts less than 2.2 times longer than length of notum and rami combined; coxosternapodeme with large anterior and posterior lobes $($ Fig. $1 \mathrm{H}) \ldots \ldots \ldots \ldots \ldots 2$

2 Notum three times longer than rami; spermathecal ducts more than 2 times longer than length of notum and rami combined (Fig. 8H) . . . . . . . . . Zavrelia pentatoma

- Notum about two times longer than rami; spermathecal ducts less than 2 times longer than length of notum and rami

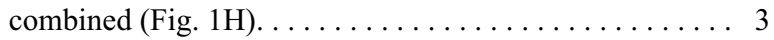

3 Cercus longer than width of seminal capsules (Fig. 6I)...... .......................... Zavrelia hudsoni

Cercus shorter than width of seminal capsules (Fig. 1H). ... . . . . . . . . . . . . . . . . . . . Zavrelia aristata

\section{Key to Zavrelia pupae and pupal exuviae}

The pupae of the following species are unknown: Zavrelia bragremia, Z. clinovolsella, and Z. tusimatijea.

1 Frontal apotome and anterior part of thorax rugose; anteriormost dorsocentral taeniate and conspicuously longer than remaining dorsocentrals (Figs 4A, B)...... Zavrelia casasi

- Frontal apotome and thorax smooth; anteriormost dorsocentral usually simple, at most slightly longer than remaining dorsocentrals (Figs 9A, B) . . . . . . . . . . . . . 2

2 Frontal tubercles absent to weakly developed; microspinule patches of TII extending anteriorly well beyond seta $D_{1}$

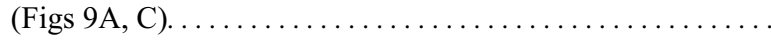
$\ldots \ldots \ldots \ldots \ldots \ldots \ldots$ Zavrelia pentatoma

- Frontal tubercles well developed, conical; microspinule patches of TII not extending anteriorly well beyond seta $\mathrm{D}_{1}$

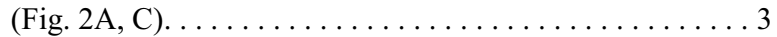

3 Abdominal segment $\mathrm{V}$ with 4 lateral taeniate setae (Fig. 2C). ..............................4

- Abdominal segment $\mathrm{V}$ with 3 lateral taeniate setae (Fig.

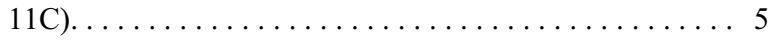

4 Microspinules on TV-VI in large parallel rectangular patches that may be connected anteriorly; pleura II and III without shagreen (Fig. 2C). .......... Zavrelia aristata - Microspinules on TV-VI in continuous patches; pleura II and III with shagreen (Zorina, 2008, Fig. 6). Zavrelia elenae

5 Prealar tubercle not developed.......... Zavrelia hudsoni - Prealar tubercle moderately to well developed, bulbous (Zorina, 2008, Figs 17, 11B) . ............. 6

6 Abdominal segment III with semi-taeniate lateral setae; tho-

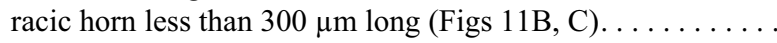
......................... Zavrelia sinica

- Abdominal segment III with simple lateral setae; thoracic horn more than $330 \mu \mathrm{m}$ long (Zorina, 2008, Figs 16, 18)... .................... Zavrelia pseudopentatoma 


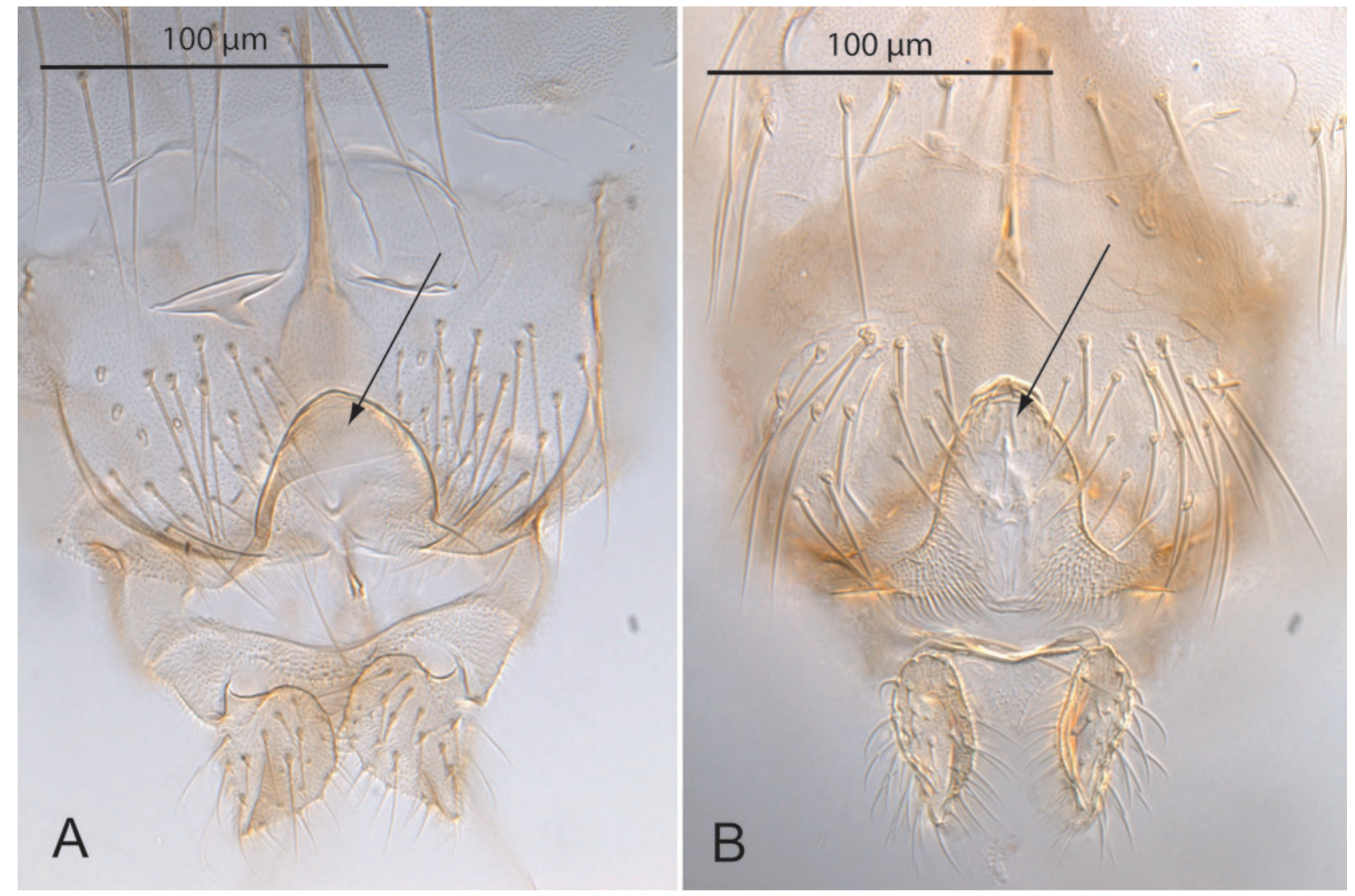

Fig. 13. Presence and absence of floor under the vaginal opening (arrow) of females from two closely related genera. (A) Stempellinella fimbriata Ekrem, 2007, paratype; (B) Zavrelia hudsoni sp. n., paratype.

\section{Key to Zavrelia larvae}

The larvae of the following species are unknown: Zavrelia bragremia, Z. casasi, Z. clinovolsella and $Z$. tusimatijea.

1 AR greater than 1 (Fig. 9D) ................. 2

- AR less than or equal to 1 (Fig. 11D).............. 3

2 Proximal Lauterborn organ on base of antennal segment 2; distal Lauterborn organ not reaching apex of antenna (Fig. 9D)..................... Zavrelia pentatoma

- Proximal Lauterborn organ on the middle of antennal segment 2; distal Lauterborn organ reaching apex of antenna (Zorina, 2008, Fig. 21)........ Zavrelia pseudopentatoma

3 Distal Lauterborn organ on long pedicel (Fig. 11D)..... . 4

- Distal Lauterborn organ on short pedicel (Fig. 2D) . . . . . . 5

4 Mandible with two spines on mola; Lauterborn organs less than $20 \mu \mathrm{m}$ long; antennal blade less than $100 \mu \mathrm{m}$ long (Figs $11 \mathrm{D}, \mathrm{G}) \ldots \ldots \ldots \ldots \ldots \ldots$. . . . . . . . . . Zavrelia sinica

- Mandible with one spine on mola; Lauterborn organs more than $22 \mu \mathrm{m}$ long; antennal blade more than $108 \mu \mathrm{m}$ long (Zorina, 2008, Figs 8, 11).......... Zavrelia elenae

5 Antennal segment $1 \quad 65-70 \mu \mathrm{m}$ long; antennal blade 125-150 $\mu \mathrm{m}$ long; AAR about 1.0 (Fig. 2D). .

.

- Antennal segment $155 \mu \mathrm{m}$ long; antennal blade c. $115 \mu \mathrm{m}$ long; AAR about 1.2 (Fig. 7C). ........ Zavrelia hudsoni

\section{DISCUSSION}

Several Zavrelia species are morphologically similar and can be difficult to separate if only one life stage is available. Also, it must be added that some of the species descriptions above are based on few specimens and that larger ranges of intraspecific variation probably will be detected if more material becomes available. Partial COI sequences (so called DNA barcodes) have proven useful for species identification and delimitation of related genera (Ekrem, 2007). Unfortunately, in this study only material of $Z$. pentatoma was found suitable for molecular analyses. Thus, whether DNA barcodes can be used to separate species of the genus Zavrelia must remain unanswered until fresh material of more species is sampled.

This and other recent studies (Zorina, 2008; Guo \& Wang, 2007) suggest some minor emendations to the previously established diagnoses of males, larvae and pupae of the genus (Cranston et al., 1989; Pinder \& Reiss, 1983, 1986). A diagnosis of Zavrelia adult females was first attempted by Sæther (1977, p. 142), and although most of his findings are confirmed by this study, none of our specimens had a large floor under the anterior part of the vagina. In fact, the lack of such a floor seems to be a good character to separate Zavrelia females from those of closely related genera, for instance Stempellinella (see Fig. 13). Among the genera within the tribe Tanytarsini, both Zavrelia and Afrozavrelia lack a vaginal floor, but these two genera can be separated by a number of other features (Harrison, 2004). The question thus remains if the female(s) with a vaginal floor identified as Zavrelia sp. by Sæther (1977) should be regarded as congeneric to the species described above. Until evidence is presented 
that associated Zavrelia females possess a vaginal floor, we are of the opinion that it should not. Indeed, females of a new hairy eyed Tanytarsini species from California, recently made available to us by Peter Cranston, possess a floor under the anterior part of vagina. However, although generally similar to Zavrelia in many aspects, this species has several other diagnostic characters that differ from what we so far have observed in Zavrelia species (e.g., macrotrichia are present on subcosta, the male anal tergite band is simple and transverse, and only one tibial comb bears a spur). Our supposition is that there are new species in the Holarctic Region that are probably best placed in one or more separate new genera rather than enlarging existing generic diagnoses. This hypothesis needs to be confirmed by phylogenetic analyses. As a result of our observations and the proposed change in the diagnostics for Zavrelia, one of the two unique synapomorphies for the tribe Tanytarsini reported by Sæther \& Roque (2004) is invalid and might alter an already unstable phylogeny of the tribe Tanytarsini. The actual effect of this and other inadequate character codings by Sæther \& Roque (2004) is currently under investigation (Ekrem, in prep.).

ACKNOWLEDGEMENTS. We would like to thank J. Casas, P. Hudson, J. Sublette, P. Sihvonen, P. Vilkamaa, M. Kotrba, J. Epler, M. Bolton, B. Caldwell, W. Giłka, P. Limbourg, P. Grootaert, X. Wang, T. Kobayashi, P.S. Cranston and P.H. Langton for providing us with material of Zavrelia and related genera, and two anonymous reviewers for their comments on an earlier version of the manuscript. This study was supported in part by the Alexander von Humboldt Foundation, Germany.

\section{REFERENCES}

Ashe P. \& Cranston P.S. 1990: Family Chironomidae. In Soós A. \& Papp L. (eds): Catalogue of Palaearctic Diptera. Vol. 2. Psychodidae - Chironomidae. Akadémiai Kiadó, Budapest, pp. 113-355.

Bause E. 1913: Preprint of Bause E. 1914: Die Metamorphose der Gattung Tanytarsus und einiger verwandter Tendipedidenarten. Ein Beitrag zur Systematik der Tendipediden. Arch. Hydrobiol. Suppl. 2: 1-139.

Bolton M. 2007: Ohio EPA Supplemental Keys to the Larval Chironomidae (Diptera) of Ohio and Ohio Chironomidae Checklist. Ohio Environmental Protection Agency, Groveport, $59 \mathrm{pp}$.

Brundin L. 1947: Zur Kenntnis der schwedischen Chironomiden. Ark. Zool. (A) 39: 1-95.

BRUNDIN L. 1948: Über die Metamorphose der Sectio Tanytarsariae connectens (Dipt. Chironomidae). Ark. Zool. 41: 1-22.

BRUNDIN L. 1949: Chironomiden und andere Bodentiere der südschwedischen Urgebirgsseen. Ein Beitrag zur Kenntnis der bodenfaunistischen Charakterzüge schwedischer oligotropher Seen. Institute of Freshwater Research, Drottningholm, Lund, $915 \mathrm{pp}$.

Cranston P.S., Dillon M.E., Pinder L.C.V. \& Reiss F. 1989: The adult males of Chironominae (Diptera, Chironomidae) of the Holarctic region. Keys and diagnoses. In Wiederholm T. (ed.): Chironomidae of the Holarctic Region. Keys and Diagnoses. Part 3. Adult Males. Entomol. Scand. Suppl. 34, pp. 353-502.
Ekrem T. 2002: Review of selected South- and East Asian Tanytarsus v.d. Wulp (Diptera: Chironomidae). Hydrobiologia 474: 1-39.

Ekrem T. 2006: A redescription of Neozavrelia cuneipennis (Edwards) comb. nov., with a checklist of Neozavrelia species of the world (Diptera: Chironomidae). Zootaxa 1153: $1-16$.

EKREM T. 2007: A taxonomic revision of the genus Stempellinella (Diptera: Chironomidae). J. Nat. Hist. 41: 1367-1465.

Ekrem T. \& S $Æ$ ther O.A. 2000: Seppia, a new Afrotropical tanytarsine genus (Diptera: Chironomidae). In Hoffrichter O. (ed.): Late 20th Century Research on Chironomidae: an Anthology from the 13th International Symposium on Chironomidae. Shaker, Aachen, pp. 79-87.

EPLER J.H. 2001: Identification Manual for the Larval Chironomidae (Diptera) of North and South Carolina. Special Publication SJ2001-SP13. North Carolina Department of Environment and Natural Resources and St. Johns River Water Management District, Raleigh, NC, and Palatka, FL, $526 \mathrm{pp}$.

Freeman P. 1958: A study of the Chironomidae (Diptera) of Africa south of the Sahara. Part IV. Bull. Brit. Mus. Nat. Hist. (Entomol.) 7: 331-357.

GıŁKA W. 2002: Tanytarsini (Diptera: Chironomidae) of Poland - a faunistic review. Pol. J. Entomol. 71: 415-428.

Goetghebuer M. 1921: Chironomides de Belgique et spécialement de la zone des Flanders. Mém. Mus. R. Hist. Nat. Belg. 8: $1-211$.

Goetghebuer M. 1932: Chironomides Paléarctiques (Diptères) conservés au Musée d'Histoire Naturelle de Vienne. Ann. Nat. Mus. Wien 46 [1931]: 91-115.

Goetghebuer M. 1937-1954: 13c. Tendipedidae (Chironomidae). b) Subfamilie Tendipedinae (Chironominae). A. Die Imagines. In Lindner E. (ed.): Die Fliegen der Palaearktischen Region. E. Schweizerbart'sche Verlagsbuchhandlung, Stuttgart, pp. $1-138+23$ plates.

Guo Y. \& WANG X. 2004: Stempellina and Zavrelia from China (Diptera, Chironomidae, Tanytarsini). Aquat. Insects 26: 183-189.

Guo Y. \& WANG X. 2007: Zavrelia bragremia sp. nov. from China (Diptera, Chironomidae, Tanytarsini). Acta Zootax. Sinica 32: 318-320.

HARRISON A.D. 2004: A contribution to the taxonomy of Tanytarsini (Diptera: Chironomidae) of Sub-Saharan Africa, with description of a new genus (Afrozavrelia) and five new species from other genera. Anls Eastern Cape Mus. 3: 1-15.

KIEFFER J.J. 1921: Chironomides nouveaux ou peu connus de la région paléarctique. Bull. Soc. Hist. Nat. Metz 29: 51-109.

KIEFFER J.J. 1923: Chironomides de 1'Afrique Équatoriale. IIIe partie. Ann. Soc. Entomol. Fr. 92: 149-204.

KOBAYASHI T. \& HAYASHI F. 2001: Inter- and intraspecific variation in body size and scutal marking pattern in three species of Conchapelopia (Diptera: Chironomidae). Entomol. Sci. 4: 39-45.

Langton P.H. 1994: If not "filaments" then what? Chironomus Newsl. Chironomidae Res. 6: 9.

LAUTERBORN R. 1905: Zur Kenntnis der Chironomiden-Larven. Zool. Anz. 29: 207-217.

MatĚna J. 1995: Polymorphism of Chironomus plumosus (Diptera: Chironomidae) males from a temperate fish-pond population. Eur. J. Entomol. 92: 699-703.

Oliver D.R., Dillon M.E. \& Cranston P.S. 1990: A Catalog of Nearctic Chironomidae. Publication 1857/B, Research Branch Agriculture Canada, Ottawa, ii +89 pp.

PinDER L.C.V. \& Reiss F. 1983: The larvae of Chironominae (Diptera: Chironomidae) of the Holarctic region. Keys and 
diagnoses. In Wiederholm T. (ed.): Chironomidae of the Holarctic Region. Keys and Diagnoses. Part 1. Larvae. Entomol. Scand. Suppl. 19, pp. 293-435.

Pinder L.C.V. \& ReIss F. 1986: The pupae of Chironominae (Diptera: Chironomidae) of the Holarctic region - Keys and diagnoses. In Wiederholm T. (ed.): Chironomidae of the Holarctic Region. Keys and Diagnoses. Part 2. Pupae. Entomol. Scand. Suppl. 28, pp. 299-456.

SÆTHER O.A. 1977: Female genitalia in Chironomidae and other Nematocera: morphology, phylogenies, keys. Bull. Fish. Res. Brd Can. 197: 1-209.

SÆTHER O.A. 1980: Glossary of chironomid morphology terminology (Diptera: Chironomidae). Entomol. Scand. Suppl. 14: $1-51$.

SÆther O.A. \& Roque F.O. 2004: New Neotropical species of Nandeva (Diptera: Chironomidae), with a phylogeny of the Tanytarsini. Tijdschr. Entomol. 147: 63-80.

SÆther O.A., Ashe P. \& Murray D.A. 2000: Family Chironomidae. In Papp L. \& Darvas B. (eds): Contributions to a Manual of Palaearctic Diptera (With Special Reference to Flies of Economic Importance). Science Herald, Budapest, pp. 113-334.
Sasa M. \& Suzuki H. 1999: Studies on the chironomid midges of Tsushima and Iki Islands, western Japan. Part 1. Species of Chironominae collected on Tsushima. Trop. Med. 41: 1-53.

Soponis A.R. 1977: A revision of the nearctic species of Orthocladius (Orthocladius) van der Wulp (Diptera: Chironomidae). Mem. Entomol. Soc. Can. 102: 1-173.

SPIES M. 1998: Three species of Tanytarsus involved in California midge nuisance problems: descriptions, ecology, and faunal relations (Insecta, Diptera, Chironomidae). Spixiana 21: 253-270.

SPIES M. 2005: On selected family-group names in Chironomidae (Insecta, Diptera), and related nomenclature. Zootaxa 894: 1-12.

Sublette J.E. \& Sublette M.F. 1973: Family Chironomidae. In Delfinado M.D. \& Hardy D.E. (eds): A Catalog of the Diptera of the Oriental Region. University Press of Hawaii, Honolulu, pp. 389-422.

ZAVŘEL J. 1934: Tanytarsuslarven und -puppen aus Niederländisch Indien. Arch. Hydrobiol. Suppl. 13: 139-165.

ZoRINA O.V. 2008: Russian Zavrelia Kieffer, 1913 (Diptera: Chironomidae), with the description of two new species. Zootaxa 1845: 60-68.

Received September 30, 2008; revised and accepted November 6, 2008 